Biogeosciences Discussions, 3, 23-70, 2006

www.biogeosciences.net/bgd/3/23/

SRef-ID: $1810-6285 / \mathrm{bgd} / 2006-3-23$

European Geosciences Union

Biogeosciences Discussions is the access reviewed discussion forum of Biogeosciences

\section{Comets, carbonaceous meteorites, and the origin of the biosphere}

\section{R. B. Hoover}

Astrobiology Laboratory, NASA/National Space Science and Technology Center, USA

Received: 24 October 2005 - Accepted: 21 November 2005 - Published: 27 January 2006

Correspondence to: R. B. Hoover (richard.hoover@nasa.gov)

(C) 2006 Author(s). This work is licensed under a Creative Commons License.
BGD

3, 23-70, 2006

Comets, carbonaceous meteorites, and the origin of the biosphere

R. B. Hoover

Title Page

Abstract

Introduction

Conclusions

References

Tables

Figures

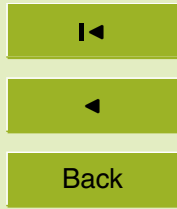

$\rightarrow$ I

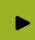

Close
Print Version

Interactive Discussion 


\section{Abstract}

The Biosphere is considered to represent the Earth's crust, atmosphere, oceans, and ice caps and the living organisms that survive within this habitat. This paper considers the significance of comets and carbonaceous meteorites to the origin and evolution of 5 the Biosphere and presents new Field Emission Scanning Electron Microscope (FESEM) images of indigenous microfossils in the Orgueil and Murchison meteorites. The discovery of microbial extremophiles in deep crustal rocks, hydrothermal vents and ancient ice has established that the biosphere is far more extensive than previously recognized. Chemical and molecular biomarkers and microfossils in Archaean rocks dhat life appeared very early on the primit sphere is closely linked with the emergence of life. The role of comets, carbonaceous meteorites, interstellar dust and asteroids in the delivery of water, organics and prebiotic chemicals to Earth during the Hadean $(4.5-3.8 \mathrm{Ga})$ period of heavy bombardment has become more widely recognized. Spacecraft observations of the chemical compoTempel 1) have established that comets contain complex organic chemicals; that water is the predominant volatile; and that high temperatures $(\sim 400 \mathrm{~K})$ can be reached on the black (albedo 0.03) nuclei when near perihelion. The microscopic dust particles in the Tempel 1 ejecta are similar in size to the particulates of the Orgueil meteorite and evidence is mounting that comets may represent the parent bodies of the $\mathrm{Cl}$ meteorites. Impact craters and pinnacles on comet Wild 2 suggest a thick crust. Episodic outbursts and jets of Halley, Borrelly, Wild 2 and Tempel 1 near perihelion indicate that localized regimes of liquid water may periodically exist beneath the thick crust of many comets. This increases the possibility that microbial life might survive in comets and therefore the widely accepted view that comets are devoid of liquid water and therefore sterile may be invalid. Consequently, the potential role of comets in the possible delivery of viable microorganisms, as well as water and organic chemicals, to Earth merits further consideration. FESEM investigations of $\mathrm{Cl}$ and $\mathrm{CM}$ carbonaceous mete-

BGD

3, 23-70, 2006

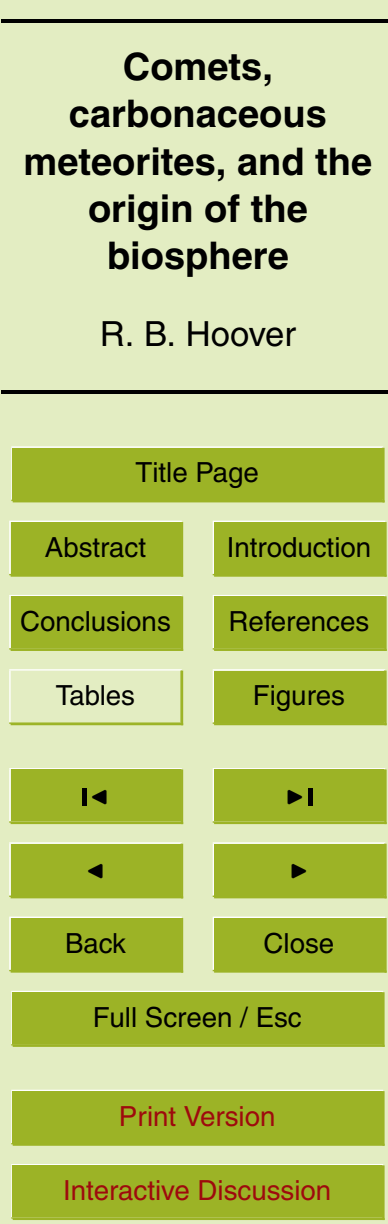

R. B. Hoover 
orites have resulted in the detection of well-preserved remains of large, complex and highly differentiated filamentous microfossils, mats, and consortia embedded in freshly fractured interior surfaces of the rock matrix. Energy Dispersive X-ray Spectroscopy (EDS) data indicate that these remains are mineralized and consequently they are 5 interpreted to represent indigenous microfossils rather than recent microbial contaminants. The detection of indigenous microfossils in carbonaceous meteorites suggests that the paradigm of the endogenous origin of life on Earth may also require reconsideration.

\section{Introduction}

10 The origin and evolution of the biosphere is one of the most profound and interesting multidisciplinary problems of modern science. It encompasses two of the most fundamental questions of Astrobiology concerning the origin and the distribution of life: Is life on Earth endogenous or exogenous? and, Is life restricted to Earth or is life a cosmic imperative?

15 Although the possibility of the exogenous origin of life was considered by von Helmholtz (1871) and Arrhenius (1903), the prevailing model during the last century has been that life arose in the primordial oceans as a result of endogenous prebiotic synthesis of organics, which is strongly dependent on the reducing state of the primitive atmosphere (Miller, 1957; Miller and Urey, 1959; Miller and Orgel, 1974). During the past two decades much information has been obtained concerning the structure, physical properties and chemical composition of asteroids, meteorites and the nuclei of comets. These observations suggest that these bodies may have played a far more significant role in the origin and evolution of the biosphere than previously recognized.

Pioneering work on the theory of origin of life (Oparin, 1924) and the nature of the 25 biosphere (Vernadsky, 1924, 1926) first appeared in Russia in 1924. Translations (Oparin, 1938, 1967; Vernadsky, 1998) have made the important contributions of these early workers to the problem of the origin of life and the nature of the biosphere more

\section{BGD}

3, 23-70, 2006

\section{Comets, carbonaceous meteorites, and the origin of the biosphere}
R. B. Hoover

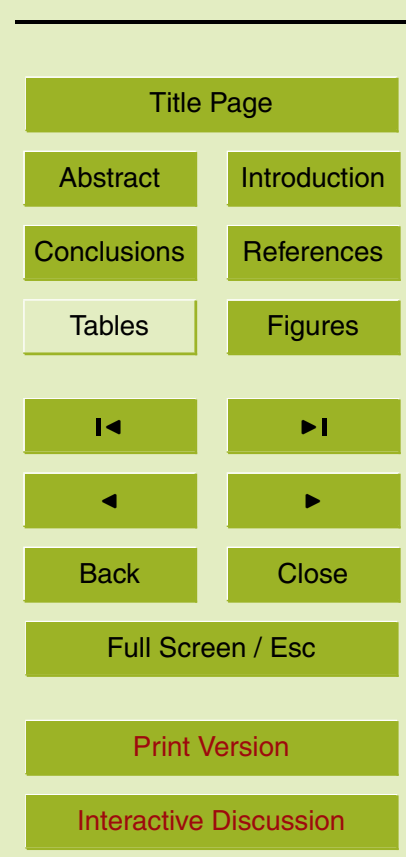


widely accessible. Vernadsky's concept of the biosphere includes living organisms on the planet as well as the inorganic elements of nature that provide the medium for their habitat. In this sense, the biosphere comprises the lithosphere, hydrosphere, and atmosphere as well as the sum of all living organisms and the myriad physical, 5 chemical, and environmental interactions between the biotic and abiotic components. The complex interrelationships that exist between the microbial world and the atmosphere, hydrosphere, cryosphere, and lithosphere are becoming better understood as research proceeds in Geomicrobiology and the Biogeosciences. Recent discoveries in Microbiology, Astrobiology, and Bacterial Paleontology have provided important new 10 information concerning the spatial, temporal, physicochemical and environmental distributions of life on Earth.

Recent discoveries have established that the biosphere is far more extensive and more complex than previously thought possible. Enormous regions of planet Earth that had long been considered "barren" and totally inhospitable to life are now known to 15 contain rich and complex ecosystems of exotic and important microorganisms. Brock and Freeze (1969) found that Thermus aquaticus was able to live at astonishingly high temperatures $\left(>80^{\circ} \mathrm{C}\right)$ in Yellowstone's Great Fountain Geyser. This discovery established that microorganisms could live at temperatures that were previously thought to destroy DNA, proteins and other life-critical biomolecules. The discovery of the Taq polymerase enzyme that protects these thermophiles has brought forth a revolution in microbiology, genomics, phylogenetics, and biotechnology. Phylogenetic analysis of ribosomal RNA sequence characterization allowed Woese and Fox (1977) to determine that living systems could be grouped into three aboriginal lines of descent or domains. In 1977, the research vessel Alvin descended to a depth of $2.6 \mathrm{~km}$ on the

25 East Pacific Rise and discovered 'black smoker' hydrothermal vents teeming with life in the deep sea floor (Corliss et al., 1979; Tunnicliffe, 1992). Chemolithotrophic sulfide oxidizing archaea growing at 260 atmospheres pressure and temperatures $>115^{\circ} \mathrm{C}$ on the mineral-rich surfaces of the chimneys were found to provide organic nutrients for a complex ecosystem of large tubeworms, spider crabs, shrimp, and molluscs. Miller
BGD

3, 23-70, 2006

\section{Comets, carbonaceous meteorites, and the origin of the biosphere}
R. B. Hoover

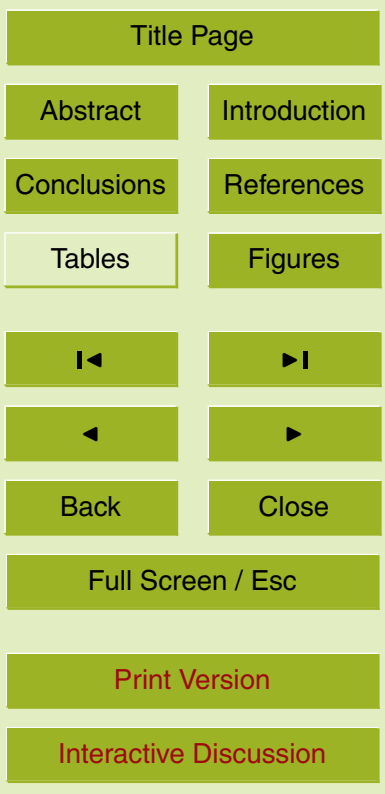


and Bada (1988) have considered the potential role of submarine hydrothermal vents in the origin of life on Earth.

\section{Astrobiological significance of the deep biosphere}

Until fairly recently it was generally accepted that microorganisms and microfossils 5 could only be associated with conditions favorable for the formation of sedimentary rocks (Urey, 1966). The presence of living microorganisms in deep subsurface aquifers and their involvement in biogeochemical cycles and the geochemical transformations of the lithosphere is well known (Kuznetsov et al., 1963; Nealson and Stahl, 1997; Ghiorse, 1988). During the past few decades, it has also been shown that sulfate 10 reducing bacteria (SRB) and hyperthermophilic and methanogenic archaea flourish in deep granitic and basalt aquifers (Olson et al., 1981; Stevens and McKinley, 1995; Pedersen and Ekendahl, 1990), deep subsurface sediments (Frederickson et al., 1989) and in hot rocks deep within the Earth's crust (Frederickson and Onstott, 1996; Onstott et al., 2003). Basalts of the deep seafloor and subsurface have been shown to contain 15 microfossils and diverse and complex microbial communities (Thorseth et al., 2001; Lysnes et al., 2004). Fisk et al. (2003) have found microbial communities and associated biomarkers in the glassy margins of the deep ocean floor basalts. It is now well established that the deep hot terrestrial Biosphere, proposed by Gold (1992) does exist within the Earth's deep crustal rocks and aquifers (Amy and Haldeman, 1997). Conse-

quently, the possibility that similar thermophilic chemolithotrophs might also be found to inhabit the hot rocks deep within other Solar System bodies cannot be logically excluded. Excellent candidates for suitable environments for chemolithotrophic microbial communities include the deep crustal rocks of Mars, and entrapped pockets of liquid water heated by tidal or volcanic processes beneath the crust of icy moons of Jupiter 25 (e.g. Europa, lo, or Ganymede), Saturn (Enceladus) or in the nuclei of many comets as they approach perihelion.

New sensors and biomolecular methodologies have provided better insights into the
BGD

3, 23-70, 2006

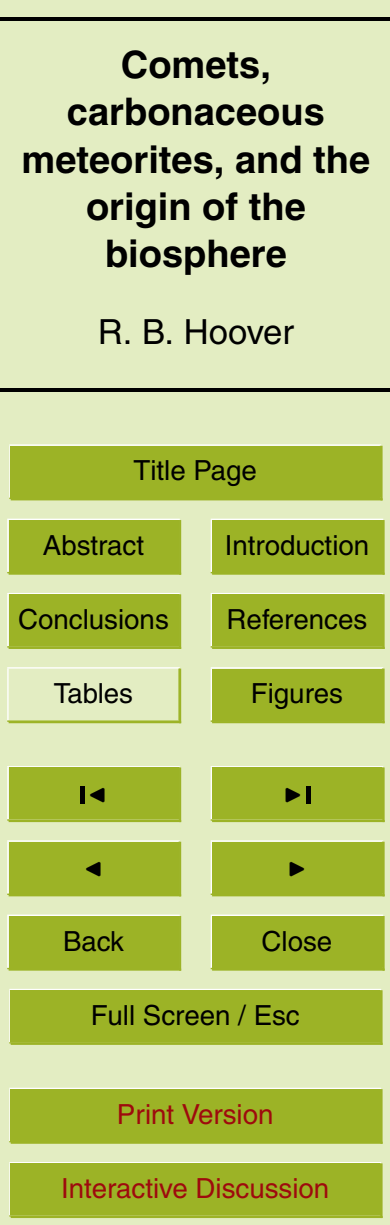

EGU 
great extent of prokaryotic life on Earth (Whitman, 1998). It is now also known that the Earth supports a vast deep, cold biosphere (cryosphere) that may contain more than $80 \%$ of the prokaryotic cells on our planet. The psychrophilic and psychrotolerant microorganisms that inhabit the cold deep sea floor sediments, permafrost, glaciers and 5 polar ice sheets typically engage in very slow growth but can be ancient and still alive. A novel psychrotolerant, facultative anaerobe (Carnobacterium pleistocenium) was isolated from the permafrost of the Fox Tunnel in Alaska (Pikuta et al., 2005) after being preserved in the ice for 32000 years. Well preserved, intact, and often viable microorganisms have also been found in ancient permafrost and in many of the horizons of the 10 deep Antarctic Ice Sheet above Lake Vostok (Abyzov, 1993; Abyzov et al., 1998, 2004, 2005; Friedman, 1994; Gilichinsky et al., 1992, 1995, 1997; Hoover, 2001; Pikuta and Hoover, 2004; Shi et al., 1997; Soina and Vorobyova, 1995; Vorobyova, et al., 1996). The ability of a wide variety of microorganisms to remain viable while frozen in ice or liquid nitrogen or in freeze-dried state of lyophilization is well known and frequently used 15 in the maintenance of microbial culture collections (Hay, 1978; Heckly, 1978; Simone and Brown, 1991). The ability of microorganisms to remain viable after exposure to high vacuum and extreme cold certainly suggests that the nuclei of comets, the polar ice caps of Mars, and the icy moons of Jupiter and Saturn are ideal sites to search for potentially viable microbes. Gas hydrates have been detected in the ice sheet overlying Lake Vostok, which suggests that clathrates might exist within the lake. This finding is significant to the potential biogeochemistry and microbial diversity of Lake Vostok. Cryopreserved microorganisms have been found in every Vostok ice core sample studied at the NASA Marshall Space Flight Center Astrobiology Laboratory. Well-preserved microbial remains were abundant even in the cores from $3627 \mathrm{~m}$, which is only about $2580 \mathrm{~m}$ above ice/water interface (Abyzov et al., 2004). Many of these microbes found in a frozen state in ancient ice and permafrost are still viable. It is now clear that the Earth's cryosphere (polar ice caps, glaciers, permafrost and deep marine sediments) is of far greater significance to the Biosphere than previously recognized. Figure 1 provides Environmental Scanning Electron Microscope (ESEM) of several cryopreserved
BGD

3, 23-70, 2006

\section{Comets, carbonaceous meteorites, and the origin of the biosphere}
R. B. Hoover

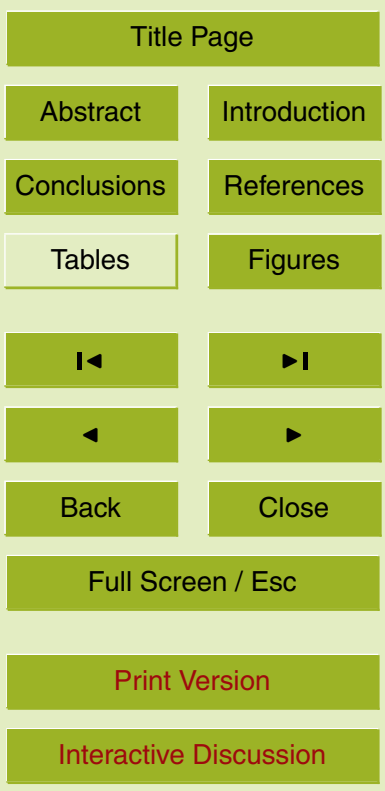


microorganisms from the deep ice cores recovered from Vostok Station, Antarctica. Figure $1 \mathrm{a}$ is a chained pair of curved rods $(0.9 \mu \mathrm{m} \times 7 \mu \mathrm{m})$ extracted from the Vostok ice core at $1203 \mathrm{~m}$ depth a Vostok ice core. This is interpreted as representing a dividing chain of unseparated cells of Desulfovibrionaceae. The size and morphology of the

5 Vostok form is consistent with the size $(0.8-1 \mu \mathrm{m}$ diameter $\times 6-11 \mu \mathrm{m}$ length) and morphological features of the large vibrion - Desulfovibrio gigas (Le Gall, 1963), which is a gram negative, sulfate-reducing obligate anaerobe. Figure $1 \mathrm{~b}$ is an image of an intact dividing diatom from a Vostok ice core at $2827 \mathrm{~m}$. Since these cells are in girdle view and still encased in polysaccharide exact identification is difficult; but they are similar 10 to the small pennate diatom Fragilariopsis which is abundant in sea ice (Hoover and Gilichinsky, 2001). Communities of the diatom Fragilariopsis nana have been found growing in brine pockets in the bottom layers of pack ice and at the base of the ice sheet near Syowa Station, Antarctica (Hoshiai, 1977). Figures 1c and 1d are FESEM images of filaments of cyanobacteria extracted from a sample of Vostok ice core from 15 the $3592 \mathrm{~m}$ horizon. The cell configuration, diameter and false branching characteristics of these large filaments are consistent with cyanobacteria in the Oscillatorales that often have thick, laminated sheaths, such as members of the genus Plectonema. Near the broken ends of the filaments (Fig. 1c) there are two $15 \mu \mathrm{m}$ disc shaped cells that were released from hollow filament. Figure $1 \mathrm{~d}$ shows the false branching and long twisted hollow sheath of the 8-15 $\mu \mathrm{m}$ diameter filaments. The filament diameter and cell size is consistent with Plectonema radiosum, which can reach lengths in excess of $1000 \mu \mathrm{m}$.

The significance of the cold seep communities and the microbes of the deep cold biosphere are becoming better understood. In 1993, Kvenvolden showed that the isotopic signature of the methane in clathrates was typically bacterial and highly variable ( $\delta{ }^{13} \mathrm{C}$ of -40 to $-100 \%$; average $\sim-65 \%$ ). It now appears that anaerobic bacteria and methanogenic archaea play a major role in the alteration of the chemistry of the oceans and in the production and release of methane into the Earth's atmosphere with resultant modifications of the global climate of the planet Earth (Zavarzin, 1984; Elvert

BGD

3, 23-70, 2006

\section{Comets, carbonaceous meteorites, and the origin of the biosphere}

R. B. Hoover

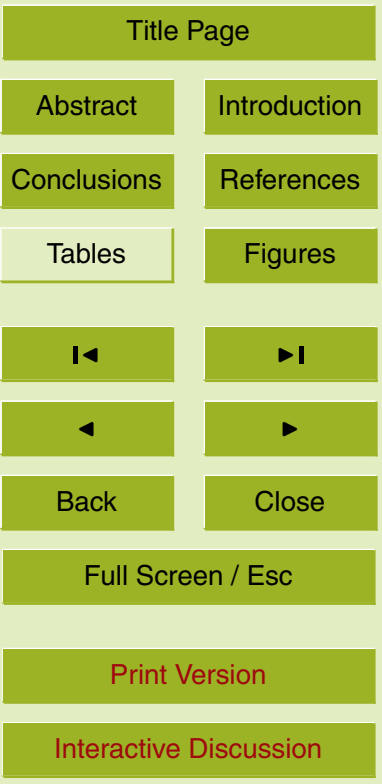


et al., 2000; Holland, 1984; Sahling et al., 2003; Lanoil et al., 2001). Using ribosomal RNA as a target for the CARD-FISH technique allowed Schippers et al. (2005) to obtain sub-seafloor sediment cell counts on Ocean Drilling Program Leg 201. Real time Quantitative Polymerase Chain Reaction 16S rRNA data showed that the bacte5 ria count $\left(10^{6}-10^{8} \mathrm{cells} / \mathrm{cm}^{3}\right)$ far outnumbered the archaea $\left(10^{2}-10^{5} \mathrm{cells} / \mathrm{cm}^{3}\right)$. They established that a large fraction of the sub-seafloor prokaryotes were alive even in the deep ( $>400 \mathrm{~m}$ ), ancient (16 Mya) sediments. The cell counts indicate that although only about $1 \%$ of the total primary production of organic carbon is available to the deep sea microorganisms, the sub seafloor sediments harbour $1.3 \times 10^{29}$ prokaryotic 10 cells $\left(2.5 \times 10^{15} \mathrm{~g}\right.$ cellular Carbon) which represent over $50 \%$ of all prokaryotic cells on Earth.

Fisher et al. (2000) have shown that the methane clathrates (crystals with concentrated pressurized gases at their core) support a complex microbial ecology and provide food for the large $(2-5 \mathrm{~cm}$ long) methane ice polychaete worms Hesiocaeca 15 methanicola. Lanoil et al. (2001) found evidence for a direct association between bacteria and archaea and the gas hydrates of the Gulf of Mexico. It is astonishing that they reported the recovery of four $16 \mathrm{~S}$ rRNA gene clones of anaerobic strains from this cold environment that exhibited $100 \%$ similarity with the 16S rRNA sequence of the aerobic, obligate thermophile Thermus aquaticus YT 1 of Yellowstone National Park.

Japan's unmanned deep-sea submersible Kaiko has obtained $11000 \mathrm{~m}$ deep samples from Challenger Deep in the Mariana Trench (Kato et al., 1997). These samples from the world's deepest sediment contained an obligate hyperbarophilic bacterium Pseudomonas bathycetes and other forms that are phylogenetically closely related to Shewanella benthica, and species of Moritella and Colwellia. Living foraminifera have been recovered from deep waters in the Weddell Sea and the Challenger Deep (Gooday et al., 2004; Todo et al., 2005). More than $70 \%$ of the Earth's surface lies under the deep sea floor sediments that contain the Earth's largest global reservoir of organic carbon and the deep terrestrial and marine biosphere may very well comprise over $60 \%$ of the Earth's total biomass. Consequently the living component of the biosphere
BGD

3, 23-70, 2006

\section{Comets, carbonaceous meteorites, and the origin of the biosphere}
R. B. Hoover

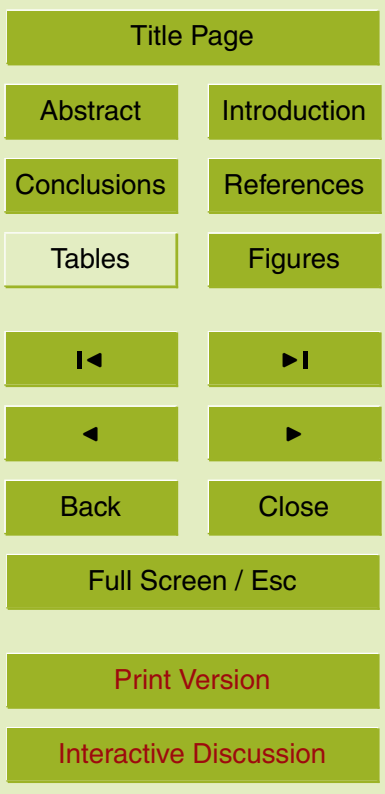


of Earth is not comprised primarily of the multicellular eukaryotic photoautotrophs and organotrophs (plants and animals) that are often associated with "life" but rather by the prokaryotic chemoautotrophs and chemolithotrophs of the deep (hot and cold) biosphere.

5 The discovery of the Earth's deep biosphere has many implications to Geomicrobiology and Astrobiology as it impacts directly on the possible existence of life elsewhere in the Cosmos. It is clearly not scientifically acceptable to conclude that life cannot exist on other Solar System bodies merely because their surfaces appear to be dry. Furthermore, the deep biosphere is protected from solar radiation and cosmic rays and hence 10 the argument that is often set forth that life could not exist on these bodies because it would be destroyed by solar ultraviolet radiation is clearly invalid. The microbiology of the Earth's deep biosphere, both marine and terrestrial, is well protected from UV and $X$-ray fluxes and the microbes that inhabit these regions have obviously evolved strategies that allow them to cope with the very high levels of natural subsurface radioactivity 15 that may occur.

Figure 2 shows Field Emission Scanning Electron Microscope (FESEM) images of some exotic microorganisms from the terrestrial deep hot biosphere (Onstott et al., 2003). These 2-D elemental $x$-ray maps are of an interesting microorganism from the carbon leader rock sample taken from a depth of $3.3 \mathrm{~km}$ depth in the Driefontein Gold Mine of Witwatersrand, South Africa. The FESEM image (Fig. 2a) can be compared with the 2-D elemental $x$-ray maps that show the bioaccumulation of heavy metals such as gold (Fig. 2b.) and uranium (Fig. 2c) overlaying the biogenic elements carbon (Fig. 2d.); oxygen (Fig. 2e) and phosphorus (Fig. 2f).

\section{Comets and the origin of the biosphere}

25 Comets are among the most interesting and important bodies of the Solar System. They may have played a crucial role in the origin and evolution of the Biosphere and the distribution of life throughout the Cosmos. Many of these wanderers of the Solar

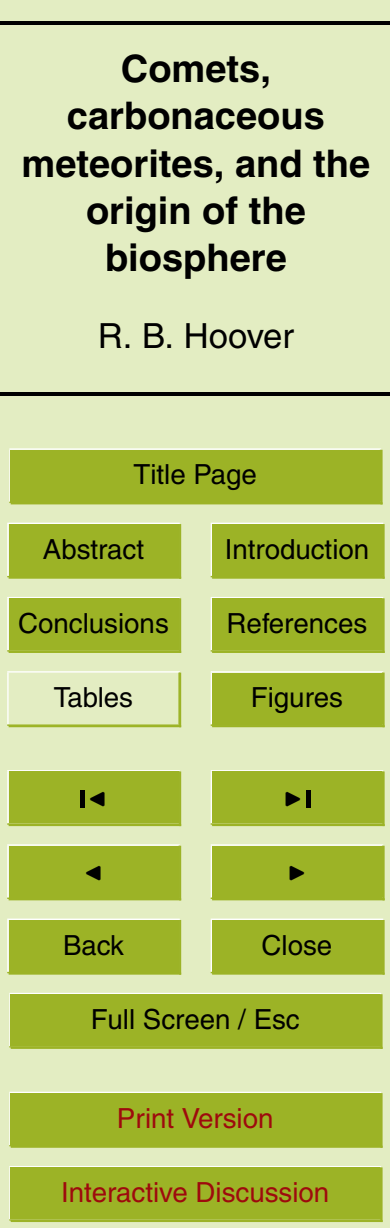


System periodically cross the orbital paths of the inner planets. As the nucleus of the comet is heated during the approach to the Sun, comets release immense volumes of particulates, water vapor, organic chemicals and other volatiles and form vast tails that can deliver cometary debris to planets, moons, and other Solar System bodies.

5 The "dirty snowball" model that was first advanced by Fred Whipple $(1950,1951)$ remains the dominant paradigm concerning the structure of the comet nucleus (Whipple, 1963). The Infrared Astronomical Satellite (IRAS) was launched in 1983 and provided important new information about the nuclei of comets. Sykes and Walker (1992) have shown that dust trails observed by IRAS in the wakes of comets have a refractory to 10 volatile ratio of the order of 3 , indicating that the nuclei of comets are much dustier than previously thought. It now appears that comets are more like "icy mudballs" than the "dirty snowballs" envisioned by Whipple. The nuclei of comets are typically small ( 10-20 km diameter), but some comets have a much larger nucleus. The great comet of 1729 (Comet Sarabat) has a $100 \mathrm{~km}$ diameter (Steel, 1997) and Hahn and Bailey 15 (1990) have argued that the very large (250 km diameter) outer solar system body 2060 Chiron might also be a comet since it has exhibited some cometary activity and it is in an unstable orbit that could lead to an Earth crossing path within 1 million years.

It is well known that comets are complex assemblages that are primarily water ice with other volatiles, organic chemicals, and dust that periodically orbit in the inner solar system. Study of the aphelia positions of the group of long-period comets ( $>200$ years periodicity) allowed Oort (1950) to deduce the existence of a large cloud of small icy bodies arranged in a spherical distribution with a mean radius of about $50000 \mathrm{AU}$. The Oort Cloud is comprised of trillions of these randomly oriented small icy bodies that serve as a vast reservoir for new comets. Passing stars or chaotic processes dislodge these icy bodies from the Oort cloud and some are sent on a trajectory to visit the inner solar system as long period comets. These long period comets include Hale-Bopp ( $P \sim 4000$ years) and Hyakatake ( $P \sim 8000$ years) and these bodies are not constrained to the ecliptic. In contrast, the group of short period comets $(\mathrm{P}<200$ years) lie near the ecliptic plane and have elliptical (typically prograde) orbits. Short period comets
BGD

3, 23-70, 2006

\section{Comets, carbonaceous meteorites, and the origin of the biosphere}
R. B. Hoover

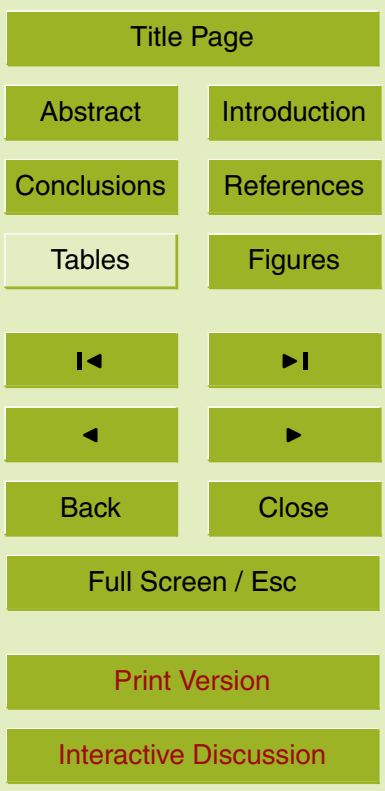


were probably induced by collisions within the Kuiper Belt (30-50 AU). It is likely that the vast numbers of comets in the Oort Cloud and Kuiper Belt did not originate within those zones, but rather accreted within the Giant Planet Zone (5-30 AU). Gravitational encounters with Jupiter and Saturn that are not close enough for the smaller bodies 5 to be accreted could have ejected them into the Oort Cloud, while encounters with Neptune and Uranus could have sent small icy bodies into the Kuiper Belt.

\subsection{Role of comets and asteroids in delivery of water and organics to the early Earth}

Both the inhomogeneous accretion model for the Earth's formation (Wetherill, 1990) and the single impact theory for the formation of the Earth-Moon system (Cameron, 10 1988; Cameron and Benz, 1989) predict that the Earth and other inner solar system bodies were depleted of volatiles when the Solar System was formed $\sim 4.6 \mathrm{Ga}$ ago. Comets, ice coated interstellar dust grains, and meteorites may play an important role in the delivery of water and organics to Earth. Watson and Harrison (2005) have interpreted the crystallization temperatures of $4.4 \mathrm{Ga}$ Zircons from Western Australia's Jack 15 Hills to indicate that liquid water oceans were present on Earth within 200 million years of the formation of the Solar System. Heavy bombardment by enormous numbers of comets and asteroids during the Hadean may have delivered water and ice to the early Earth and helped to cool the crust and form the early oceans. The cratered surface of the moon provides clear evidence of the intense Hadean bombardment of the inner 20 planets and moons by asteroids, meteoroids, and comets during the early history of the Solar System.

Delsemme (1998) has pointed out that the study of the water molecules of comets Halley, Hale-Bopp and Hyakutake have shown that their deuterium enrichment of comets is about twice that of seawater. The orbital characteristics indicate that these comets most probably originated in the zones of the outer planets. The deuterium enrichment of seawater is quantitatively consistent with an origin from a cometary bombardment of the primitive Earth by components of the Jupiter family of comets. The recognition that of all these bodies only the comets arrive from the volatile-rich outer

BGD

3, 23-70, 2006

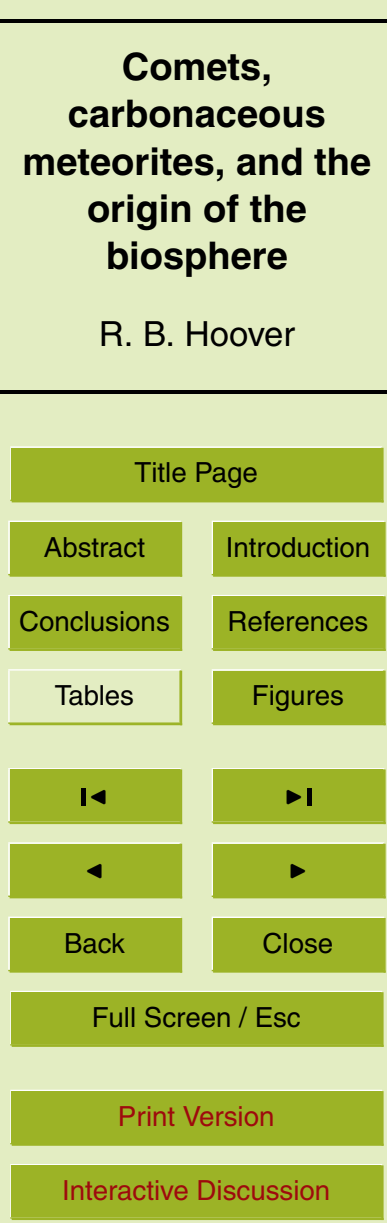

EGU 
regions of the solar system led Oró (1961) to suggest that comets delivered water and organic molecules to the early Earth and played an important role in the origin of life (Oró and Lazcano, 1997). It is now becoming clear that some of the asteroids may have also played a significant role in the delivery of water and organics to early Earth. 5 Thomas et al. (2005) have used the Hubble Space Telescope to investigate Ceres, the largest known asteroid. Computer models indicate that $930 \mathrm{~km}$ diameter asteroid Ceres could have a mantle rich in water ice surrounding a rocky core. If the mantle accounts for $25 \%$ of the asteroid mass, the total amount of water on Ceres would exceed the amount of freshwater on Earth. There also exists evidence that comets may have 10 delivered extraterrestrial amino acids to the early Earth in addition to their contributions to the formation of the oceans (Delsemme, 1997; Chyba, 1990a, b). Oró (1960) demonstrated the prebiotic synthesis from $\mathrm{HCN}$ of biochemical monomers, amino acids and adenine and advanced the hypothesis that this represented the abiotic synthesis of biochemicals that preceded the first organisms in accordance with the Oparin (1924, 15 1938) theory of the Origin of Life.

\subsection{Evidence for liquid water on comets}

It is now widely accepted that even though comets are rich in water ice they are entirely devoid of liquid water. As comets approach the Sun and the temperature of the nucleus exceeds $200 \mathrm{~K}$ the water ice is thought to be converted directly to gas (water vapour) by sublimation without transition through the liquid phase. For this reason it is generally thought that comets would not be capable of harbouring microbial life, since the metabolism and active growth of all known life forms on Earth seems to be predicated upon the existence of liquid water. However, the phase diagram of water clearly shows that liquid water would exist in cometary nuclei, if cavities and pockets that are of rock, ice and dust. The unexpectedly high dust content (A'Hearn, 2005b) found in the nucleus of Comet Tempel 1 could facilitate the formation of permafrost-like structures in which water ice cements together the dust grains to reduce the permeability

BGD

3, 23-70, 2006

\section{Comets, carbonaceous meteorites, and the origin of the biosphere}

R. B. Hoover

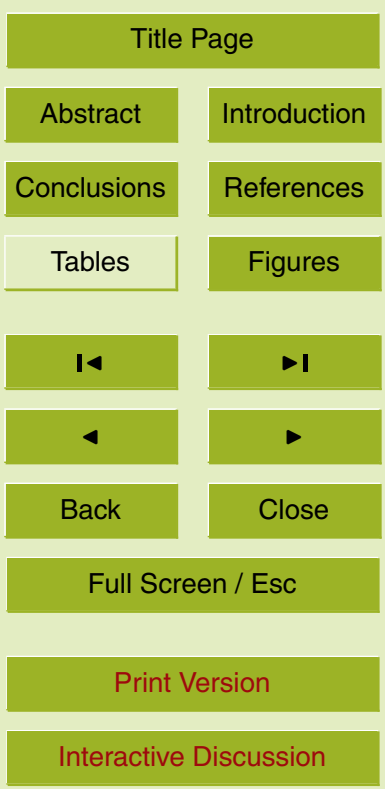


of the surface regimes and inhibit the free flow of gas. Observations of comets with the Hubble telescope and the European Southern Observatory Very Large Telescope, which recorded an image of comet 1P/Halley in March 2003 when it was over $28 \mathrm{AU}$ from the Sun, have provided additional information about the behavior of icy bodies in 5 the distant regions of the solar system. Comets do not develop comae or tails until they approach the Sun closer than roughly the orbit of Jupiter ( $5 \mathrm{AU})$. As the comet recedes beyond this distance (sometimes referred to as the "snow line") the volatiles solidify and the coma and tail disappear. The coma is a dense cloud of water vapor, carbon dioxide and neutral gases released from the nucleus and surrounded by a hy10 drogen cloud ( $>10^{6} \mathrm{~km}$ diameter). As comets approach perihelion they develop a long, curved, dust tail $\left(\sim 10^{7} \mathrm{~km}\right)$ comprised of dust particles driven off the nucleus by escaping gases and a straight plasma ion tail (sometimes with rays and streamers) formed by interactions with the solar wind and can extend for several hundred million kilometers.

An international armada of spacecraft (Vega 1, Vega 2 - Russia; Giotto - Europe; 15 Suisei, Sakigake - Japan) converged on Comet P/Halley in March of 1986. These space missions obtained important data concerning the nature, characteristics, temperature, and chemical composition of the nucleus and coma of Halley. Measurements of the dayside surface temperature showed the nucleus of Comet P/Halley to be far above the $200 \mathrm{~K}$ sublimation temperature of ice in vacuum. Vega 1 and 2 passed within $8000 \mathrm{~km}$ of the nucleus of comet P/Halley. The Vega images showed a dark nucleus $\sim 14 \mathrm{~km}$ long with a rotation period of $53 \mathrm{~h}$ and two bright jets emitting from the comet. The Vega Dust Mass Spectrometer indicated that the Halley nucleus material had a composition similar to that of carbonaceous meteorites and detected clathrate ices. The primary volatile is water ice $(75 \%-80 \%)$. The Vega images showed a surprisingly dark nucleus with two bright jets. Four days later, the Halley Multicolor Camera of the ESA Giotto spacecraft obtained spectacular images from $600 \mathrm{~km}$ showing the full contour of the nucleus (Fig. 2a). Giotto determined that the $16 \times 8 \times 8 \mathrm{~km}$ nucleus of Comet P/Halley is one of the darkest objects in the solar system (albedo $\sim 0.03$ ). This extremely low albedo is similar to that of the D Asteroid 368 Haidea and to that of the
BGD

3, 23-70, 2006

\section{Comets, carbonaceous meteorites, and the origin of the biosphere}
R. B. Hoover

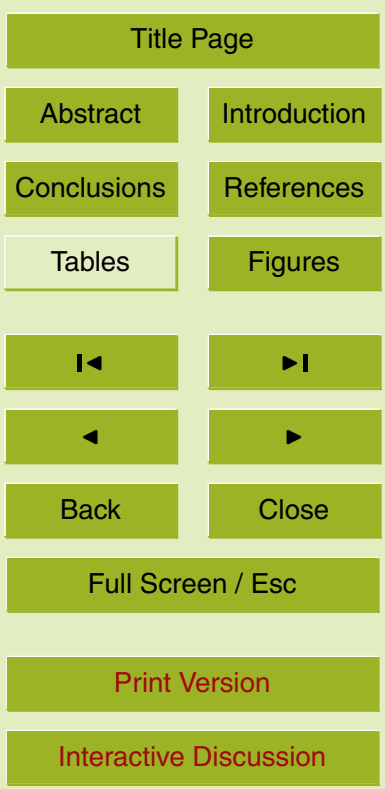


carbonaceous meteorites. As comets lose ices they develop an inert, jet-black, crust from the less volatile material (Wickramasinghe and Hoyle, 1999; Wallis and Wickramasinghe, 1991). ISO data obtained on 27 September 1996 revealed that water was the primary volatile (75-80\%) of the $40-50 \mathrm{~km}$ diameter nucleus of Comet Hale-Bopp.

5 When Hale-Bopp was 444 million $\mathrm{km}$ from the Sun it was found to be releasing water vapor in jets, along with dust and minor fractions of simple gases and volatiles from clathrate ices (e.g. $\mathrm{CO}, \mathrm{CO}_{2}, \mathrm{CH}_{4}, \mathrm{NH}_{3}$ and $\mathrm{H}_{2} \mathrm{CO}$ ) at a rate of $2 \times 10^{9} \mathrm{~kg} / \mathrm{s}$. Volatiles and solids are well mixed throughout the nucleus of a new comet during its first approaches to the Sun.

10 The Vega IR spectrometers (Emerich et al., 1987) determined the temperature of the nucleus of Comet P/Halley to be $300 \mathrm{~K}-400 \mathrm{~K}\left(27-127^{\circ} \mathrm{C}\right)$, which was far hotter than expected and it was concluded that comet Halley had a thin layer surface covering the icy body. However, the implications of such high temperature regimes on the cometary nucleus may be much more significant as this result can be interpreted as evidence for 15 liquid water in the cometary nucleus. From strictly thermodynamical considerations it is not easy to explain how the porous crust remains at a temperature $300-400 \mathrm{~K}$, while continuously being suffused by the very cold $200 \mathrm{~K}$ water vapor leaving the interior of the comet by sublimation. These high temperatures suggest that the flow of the very cold gases from the interior of the nucleus must have been restricted in order for the low albedo crust to become so hot.

However, if the outer regime of the comet nucleus is not completely permeable to the escaping gas, constraint of the water vapor liberated as interior ice sublimates would result in an increase of the gas pressure. From the triple point of water, it is clear that wherever pressures in excess of 10 millibars occur, the phase change of water is from ice to liquid to gas. The high temperatures and sudden flaring and jets associated with the nuclei of several comets provides evidence of high internal pressures within the nucleus. Consequently, it should be possible for the transient formation of pools and films of liquid water in enclosed sub-crustal cavities and crevasses within the ice/rock matrix beneath the hotter regions of the exterior surface. (Hoover et al., 2004a, b;
BGD

3, 23-70, 2006

\section{Comets, carbonaceous meteorites, and the origin of the biosphere}
R. B. Hoover

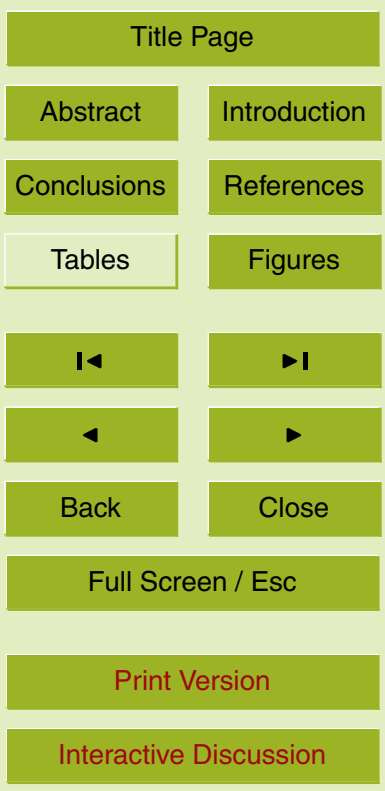


Sheldon and Hoover, 2005). It is proposed that the bright geyser-like jets that have been frequently observed are the result of a rapid release of water ice and vapor, volatiles and dust that result from crust failure when the internal pressure exceeds the structural strength of the region constricting the escaping gas. This would result in 5 a dramatic change in the albedo and the bright, geyser-like jets of water vapor, gas, and dust are seen to escape. Figure $3 a$ shows bright regions and jets escaping from the dark nucleus of Comet 1P/Halley as recorded in 1986 by the Halley Multicolor Camera (HMC) on the ESA Giotto spacecraft. Similar jets of dust and gas (not shown) were seen escaping from the nucleus of Comet P/Borrelly on 22 September 2001. 10 Figure $3 b$ shows jets (of water vapor and dust) escaping from Comet 9P/Tempel 1 shortly before impact of the Deep Space 1 probe. Comet Tempel 1 is thought to be a typical member of the Jupiter family of comets. The Hubble Space Telescope and the Deep Impact spacecraft observed dramatic outbursts from Tempel 1 on 14, 22, and 30 June 2005 during the approach of the Deep Impact Spacecraft. Both water and carbon dioxide were observed to increase substantially and the projected expansion velocity of the dust ejecta during the 22 June outburst was $0.16 \mathrm{~km} / \mathrm{s}$ (A'Hearn et al., 2005a). The frequent outbursts of Tempel 1 were associated with an area near local sunrise (A'Hearn et al., 2005b).

These observations of Tempel 1 are totally consistent with the scenario presented 20 herein, that localized heating results in the melting and evaporation of water and other volatiles and that crustal failure occurs when the internal pressures exceed the structural strength of the crust. The Deep Impact mission also observed that the abundance of organics and water increased dramatically immediately after impact and that the impact was associated by a release of a large volume of microscopic sized particulates

- "too many to have been pulverized by the impact itself" (A'Hearn et al., 2005b). (The Orgueil meteorite is composed of microscopic sized $(0.1$ to $100 \mu \mathrm{m})$ particulates that are cemented together by water-soluble evaporite minerals such as magnesium sulfate.) Observations by Sugita et al. (2005) with the Subaru Telescope indicate that the Tempel 1 dust was accelerated by the evaporation and expansion of volatiles. Fig-
BGD

3, 23-70, 2006

\section{Comets, carbonaceous meteorites, and the origin of the biosphere}
R. B. Hoover

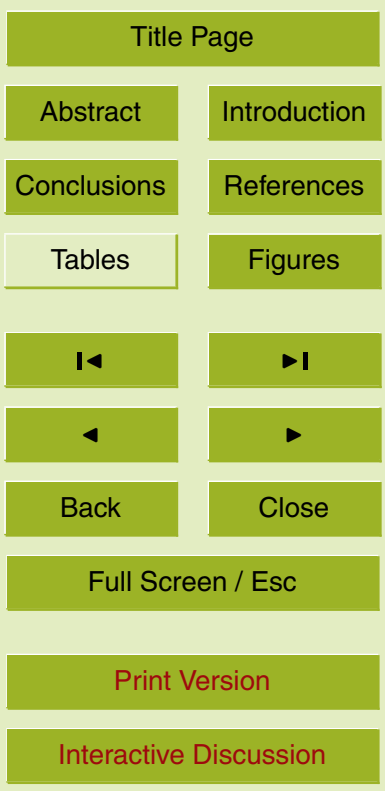


ure $3 \mathrm{~b}$ is an image recorded by the impact target sensor showing jets of dust and gas escaping from Comet 9P/Tempel 1 thirty minutes before the Deep Impact space probe collided with the comet nucleus. Craters are seen on the nucleus of Tempel 1 just before impact (Fig. 3c).

5 A pattern of jets, including two apparently from the nightside, was recorded by the Stardust probe when it approached within $500 \mathrm{~km}$ from Comet 81P/Wild-2 (Fig. 3d). One of the Stardust images (Fig. 3e) also revealed the presence of cliffs and pinnacles to heights of $100 \mathrm{~m}$. This image clearly indicates that the black crust of Wild-2 is very thick and durable. Such a thick crust is certainly not consistent with the fluffy 10 "dirty snowball" model and ice build up could block pores and render this thick crust incapable of allowing the free passage of gas and water vapor. Consequently, internal pressures would increase within the nucleus; thereby making it possible for liquid water to accumulate in pockets and pools beneath the crust and in cavities within the comet's crust. Studies of cryoconite microbial ecosystems have provided new data concerning the microbial compositions of communities that thrive in water films surrounding rocks embedded in the ice of glaciers and the polar ice caps. Hoover et al. $(1986,2001$, $2004 a, c)$ have suggested that pockets and pools of meltwater trapped in interior cavities just beneath the comet crust could sustain pressures sufficiently high to allow the existence of liquid water for periods of time sufficient to allow growth of microorganisms and the formation of microbial mats.

\section{Carbonaceous meteorites and the origin of the biosphere}

One of the most important problems concerning the origin of the biosphere is the fundamental question of whether life on Earth is endogenous or exogenous. The prevailing paradigm has been that Earth life is endogenous and a prodigious body of work has been carried out in order to understand the fundamental transition from abiogenic elements on pre-biotic Earth to the complex assemblages of living cells and organisms. However, due to the continuous influx of meteorites, interstellar dust par-

BGD

3, 23-70, 2006

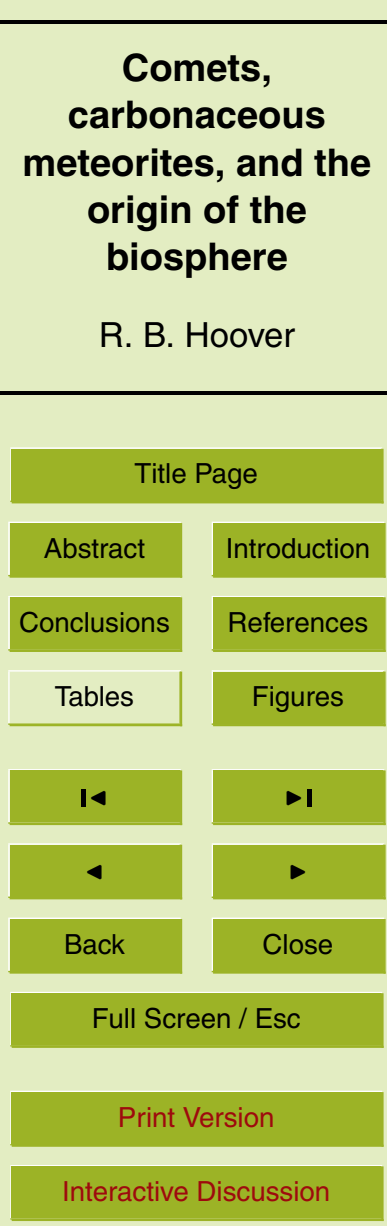

EGU 
ticles and cometary debris, the biosphere of Earth is obviously an open (rather than a closed) system. Hoyle and Wickramasinghe (2000) have extensively considered the possible delivery of complex organic chemicals and even intact and viable microorganisms to Earth via the influx of cometary debris, meteorites, and interstellar dust 5 particles. The existence of a large array of biochemicals in carbonaceous meteorites has recently led to serious considerations of the role of these exogenous sources in the origin of Life on Earth (Chyba, 1990b; Chyba and Sagan, 1997; Delaye and Lazcano, 2005). Biomarkers and fossils of ancient stromatolites and well preserved filamentous prokaryotes and mineralized remains of mats indicate that assemblages analogous 10 to modern cyanobacterial mats have existed since the Archaean. Schidlowski (1988, 2001) has provided evidence that the biological modulation of the geochemical carbon cycle had been established by $3.8 \mathrm{Ga}$ ago. This suggests that life first appeared on Earth during the period of heavy bombardment by comets and meteorites in the Hadean. The detection of evidence for the indigenous mineralized remains of filamentous prokaryotes (similar to cyanobacteria) in carbonaceous meteorites indicates that the possibility of an exogenous origin of life via the delivery of intact and viable microbiota to the early oceans of our planet cannot be ruled out.

\subsection{Early reports of evidence for microfossils in carbonaceous meteorites}

Several decades ago, mass spectrometry analysis of the organic chemicals of the 20 Orgueil $\mathrm{Cl}$ carbonaceous meteorite revealed a pattern of molecular fragments that were very much like those of well known biogenic hydrocarbon mixtures (Nagy et al., 1961). Microbiological examination of the Orgueil and Ivuna carbonaceous meteorites by Claus and Nagy (1961) resulted in the detection of microscopic ( 4-10 $\mu \mathrm{m}$ diameter) spherical "organized elements" considered to resemble algae. Similar bodies were 25 not found in the Holbrook (L6) and Bruderheim (L6) ordinary chondrites. This paper (and the lengthy debate that followed) highlighted the fundamental problem of establishing the biogenicity of simple spherical forms such as the "organized elements". Timofeev (1963) studied the Murray carbonaceous meteorite and also reported the
BGD

3, 23-70, 2006

\section{Comets, carbonaceous meteorites, and the origin of the biosphere}
R. B. Hoover

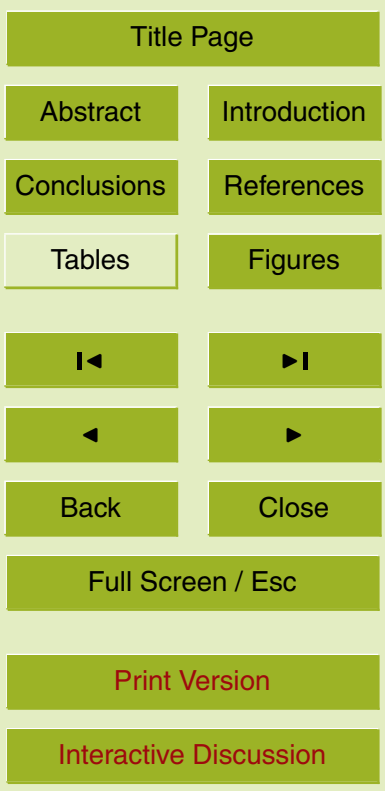

EGU 
presence of spherical carbonized acritarch-like forms. However, since simple spherical objects can be easily produced by abiotic processes, it is not possible to easily interpret them as unambiguously biogenic microstructures unless accompanied by other strong evidence of biogenicity (e.g. complex recognizable array of spines, associated DNA, 5 lipids, etc). The "organized elements" were immediately discounted as mineral grains or pollen contamination (Anders and Fitch, 1962; Fitch et al., 1963; Fitch and Anders, 1963a, b). Nagy (1975) provided an extensive description of carbonaceous meteorites, chemical biomarkers and many details concerning the "organized elements" controversy. Claus and Nagy (1961) failed to recognize that their Type 5 "organized element" 10 was in fact a pollen contaminant. This very serious error undoubtedly contributed to the presently widely accepted belief that the "organized elements" were nothing more than pollen contaminants (Rossignol-Strick et al., 2005). However, Rossignol-strick and Barghoorn (1971) conclusively established that the Orgueil meteorite contained indigenous hollow spheres that could not be dismissed as pollen. They interpreted these forms as more likely to have resulted from abiotic organic coatings on mineral grains. Their research highlighted the fundamental problem with simple spherical forms - they are easily produced by abiotic processes and therefore cannot be easily interpreted as unambiguous biogenic microstructures or microfossils.

The 'organized elements' debate was effectively terminated when Anders et 20 al. (1964) reported that a 'pristine' sample of the Orgueil stone had been intentionally contaminated with coal fragments, reed seed-capsules, and a glue-like collagen. This could explain all of the organic chemicals (humic acids, amino acids, kerogen, etc.) and the putative microfossils reported found in the Orgueil meteorite. The report of the discovery of a hoax concerning microfossils in the meteorite effectively extin25 guished all serious scientific investigations seeking evidence for biogenic materials and microfossils in meteorites for over three decades. During this long hiatus only a few papers concerning microfossils in meteorites appeared. Tan and Van Landingham (1967) published TEM images of acid-resistant forms in Orgueil with electron dense solid bodies aligned along their longitudinal axis in a manner very similar to the "chain
BGD

3, 23-70, 2006

\section{Comets, carbonaceous meteorites, and the origin of the biosphere}
R. B. Hoover

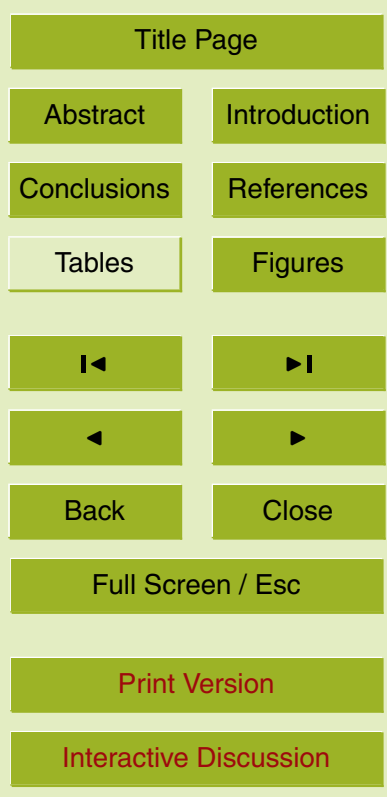


of pearls" configuration of magnetosomes in the magnetotactic purple sulfur bacterium Rhodopseumonas rutilis (Hoover, 2005). Urey (1966) reviewed the evidence for biological materials in carbonaceous meteorites and noted that the organic substances found therein resembled those found in ancient terrestrial rocks and hence were unlike 5 recent contaminants. He remarked: "If found in terrestrial objects, some substances in meteorites would be regarded as indisputably biological. ... Those of us who had been working on meteorites for some years were certain that there could not be the residue of living things in them. Had the meteorites had the composition of sedimentary rocks on the Earth, no great surprise would have been expressed." Although it 10 was accepted that carbonaceous meteorites contained indigenous organic chemicals and biogenic materials, the possibility of microfossils in meteorites challenged existing paradigms concerning the properties of life on Earth, volcanic rocks, and meteorites. Hyperthermophilic microorganisms and the rich assemblage of life in hydrothermal vents associated with sea floor volcanoes were unknown. Furthermore, although many of the meteoritic minerals are associated with high temperature processes, the $\mathrm{Cl}$ and $\mathrm{CM}$ carbonaceous chondrites contain clay and evaporite minerals that can only be formed at low temperatures and in association with liquid water.

Carbonates and sulfates, which are prominent components of the $\mathrm{Cl}$ and $\mathrm{CM}$ carbonaceous meteorites, provide clear evidence of aqueous activity on the parent body of these meteorites (Fredriksson and Kerridge, 1988). The mineralogical and petrographic evidence indicates the presence of a low temperature, hydrous environment (Boström and Fredriksson, 1966; Kerridge, 1967). Oxygen isotope data (Clayton and Mayeda, 1984) also indicate that the $\mathrm{Cl}$ and $\mathrm{CM}$ carbonaceous chondrites were not formed by nebular condensation but rather by secondary, low temperature, aqueous alteration of the meteorite parent body. The nature of these carbonaceous meteorites suggests aqueous activity in a planetessimal regolith subjected to impact induced brecciation and turnover of the permafrost-like environment (Dufresne and Anders, 1962).

The modern research in Astrobiology, microbial extremophiles, and the search for microfossils in meteorites was inspired by the McKay et al. (1996) report of the de-

BGD

3, 23-70, 2006

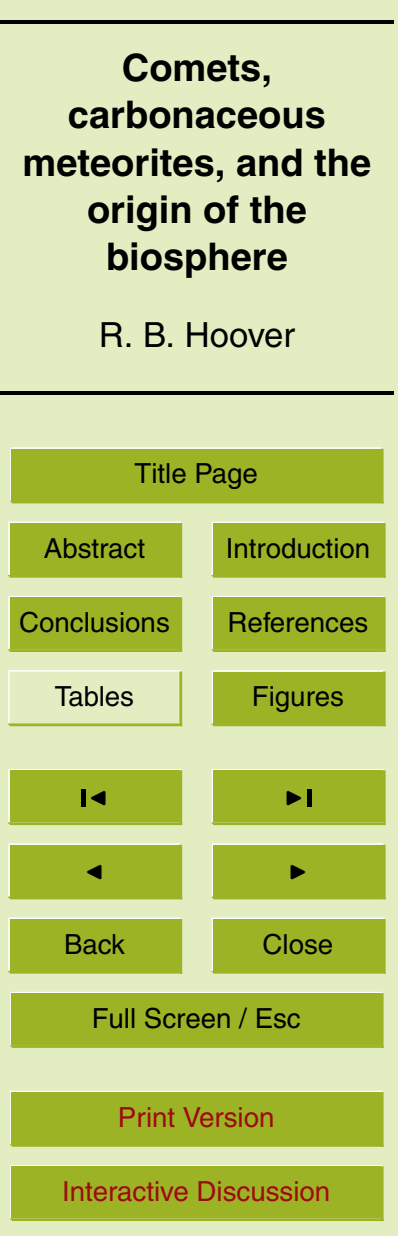

EGU 
tection of chemical biomarkers and the possible remains of fossilized nanobacteria in ALH84001, a SNC meteorite from Mars. Although the putative microfossils in ALH84001 were found in close association with a variety of mineral and chemical biomarkers, their minute size scale and extremely simple morphology has also pre5 vented the conclusive establishment of their biogenicity.

\section{Recent evidence for microfossils in carbonaceous meteorites}

During the past decade, scanning electron microscopes have been used in an extensive search for evidence of microfossils in carbonaceous meteorites. Investigations have been carried out in the United States at the NASA/Marshall Space Flight Center 10 (Hoover, 1997, 2005; Hoover and Rozanov, 2003; Hoover et al., 1998, 2003, 2004a) and in Russia at the Paleontological Institute, Russian Academy of Sciences (Zhmur et al., 1997; Gerasimenko et al., 1999; Rozanov and Hoover, 2002). The work at NASA has involved the study of the freshly fractured interior surfaces of most major groups of carbonaceous meteorites: Cl1 (Alais, Ivuna \& Orgueil); C2 Ungrouped (Tagish Lake); 15 CK4 (Karoonda); CM2 (Murchison, Mighei, Murray \& Nogoya); CO3 (Rainbow, Kainsaz \& Dar al Gani 749); CR (Acfer 324); and CV3 (Allende, Efremovka). Microstructures in the size range $(50-400 \mathrm{~nm})$ of the putative microfossils of ALH84001 have been detected in all of these meteorites. However, since these nanometer-scale objects can not be definitively and conclusively associated with known bacteria and are of uncertain

biogenicity, they have not been the focus of this research. Even larger $(1 \mu \mathrm{m}-20 \mu \mathrm{m})$ spherical bodies have been found embedded in the meteorite matrix of several of the $\mathrm{Cl}, \mathrm{C} 2, \mathrm{CM}, \mathrm{CO}$ and $\mathrm{CV}$ carbonaceous meteorites. Many of these mineralized objects are similar in size and morphology to known bacteria (cocci) and chroococoid morphotypes of unicellular, isopolar cyanobacteria (Order: Chroococcales) and may have been of biological origin and represent valid microfossils. However, since many abiotic processes can produce spherical microstructures it is difficult to obtain clear and convincing evidence to establish their biogenicity and therefore these spherical forms

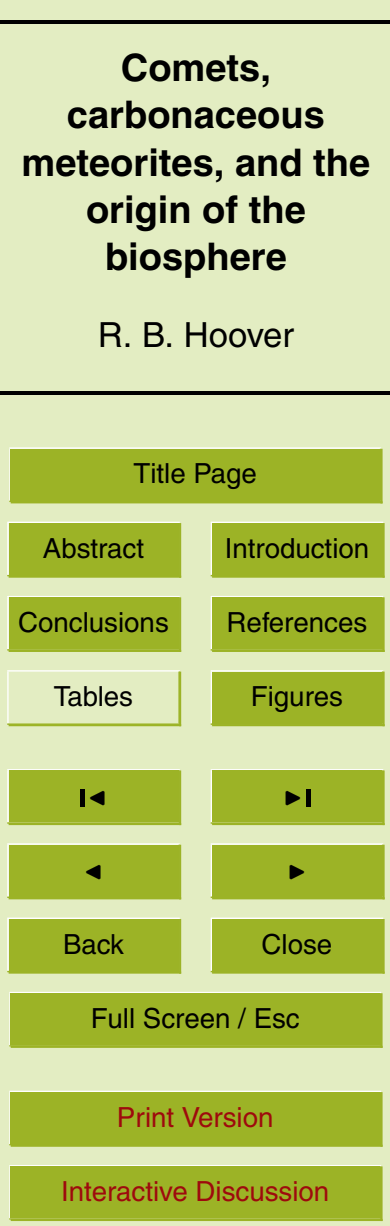


have also been discounted. Indeed, many clearly abiotic spherical forms in this size range are often found in the Apollo 17 Lunar Dust samples that were used as negative controls. EDS elemental analysis clearly revealed that these spherical bodies resulted from the effects of surface tension on liquid droplets of melted lunar glass and silicate 5 minerals that re-solidified after being vaporized by impacts on the lunar surface.

\subsection{Contamination controls}

Rigorous protocols, methodologies, and null controls were employed at the NASA Marshall Space Flight Center during the study of indigenous microfossils in carbonaceous meteorites. These were instigated in order to protect the precious meteorite specimens 10 from contamination and to recognize contaminants whenever they were encountered. Immediately prior to sample preparation, all containers, SEM stubs, tweezers and other tools that would be used were flame sterilized. For short term storage, the meteorite samples were maintained in sealed containers in enclosed desiccator cabinets. For long term storage, the meteorite samples were sealed in sterile glass tubes that had been purged and filled with filtered dry nitrogen, The sealed tubes were then stored in freezers maintained at $-80^{\circ} \mathrm{C}$, which is sufficiently cold to prohibit growth of all known likely microbial contaminants (bacteria, archaea, and fungi). Since fusion crusts, old cracks, and fissures in the meteorites could have become contaminated with post arrival biological materials, the research at NASA/MSFC has been primarily restricted to the study of interior surfaces of freshly fractured meteorite samples. Prior work has clearly shown that contaminants (such as pollen) can easily be introduced and concentrated during the acid maceration techniques that were used in many of the early meteorite studies. These techniques have never been used during this research. It is important to note that although it is widely believed that all carbonaceous mete25 orites are heavily contaminated by "pollen grains", during the research carried out at NASA/MSFC since 1996 not even one pollen grain has been found in the interior surface of any of the meteorites or the Archaean or Proterozoic rocks that have been investigated.

BGD

3, 23-70, 2006

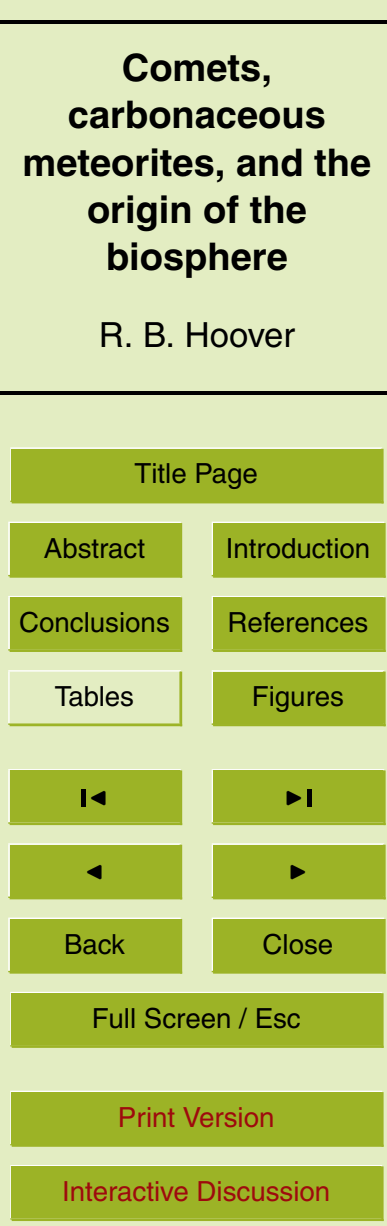


Energy Dispersive X-Ray Analysis (EDS) and 2-D x-ray maps of elemental distributions were used to determine elemental abundances. In order to develop the data base needed to recognize valid microfossils and to distinguish them from recent microbial contaminants, extensive FESEM, ESEM and EDS studies have been carried out 5 on living microbial extremophiles and cyanobacteria in axenic cultures and environmental communities and assemblages. Studies have also been conducted on cryopreserved remains of cyanobacteria, sulfate-reducing bacteria and fungi in permafrost and deep ice cores and the mineralized remains of indigenous microfossils of bacteria and cyanobacteria in many different Proterozoic and Archaean rocks.

10 A variety of non-carbonaceous meteorites were studied as negative controls. These included several ordinary chondrites - L4 (Nikolskoye, Barratta); L/LL6 (Holbrook); iron meteorites - IIIAB Medium Octahedrite (Henbury); and selected meteorites collected in the Thiel Mountains (TIL99001-TIL99019) during the Antarctica 2000 Expedition (Sipiera and Hoover, 2001); and a diogenite (calcium poor achondrite) from Tunisia - DIO 15 (Tatahouhine) and Lunar Dust collected during the Apollo 17 Mission. The negative controls also included some terrestrial rocks that can be expected to be free of microfossils and recent biological materials (e.g. lava collected only hours after it solidified during the 2002 effusion of the Pu'u 'O'o crater of Kilauea Volcano, Hawaii). Not one of the negative controls has been found to contain forms similar to the biogenic microstructures and recognizable microfossils that were found embedded in freshly fractured interior surfaces of most of the carbonaceous meteorites studied. Many of the microfossils that have been found embedded in the carbonaceous meteorite are mineralized and bear elemental signatures of meteorite rock matrix. Although they are often mineralized, most contain a detectable carbon signature and some are almost entirely carbonized and exhibit $\mathrm{O} / \mathrm{C}$ ratios comparable to kerogen and coal. Many of the microfossils found are recognizable as filamentous prokaryotes that are interpreted as morphotypes of known groups of filamentous cyanobacteria and bacteria.
BGD

3, 23-70, 2006

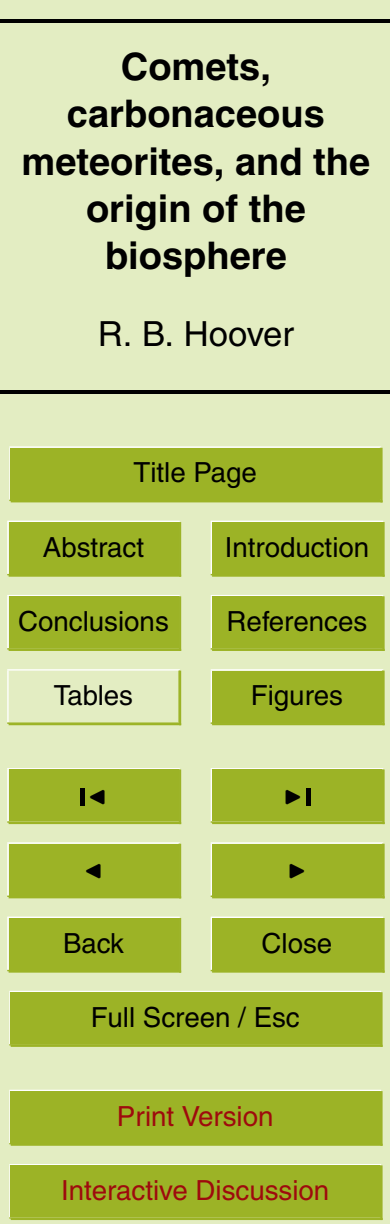

R. B. Hoover 
Meteorite studies at NASA/MSFC were carried out with the ElectroScan Corp Environ3, 23-70, 2006 mental Scanning Electron Microscope (ESEM) and the Hitachi S-4100 Field Emission Scanning Electron Microscope (FESEM). These instruments are ideal for imaging un5 coated samples of rocks and Astromaterials as well as living and freshly killed cells. The ESEM operates at a water vapor partial pressure of 10 Torr and can image nonconductive samples without building up a negative charge. It is capable of magnification from 90X to $100000 \mathrm{X}$ with an operating voltage of 10 to $30 \mathrm{keV}$. The Noran Instruments Energy Dispersive Spectrometer is capable of detecting light elements ( $Z$ above Boron). The Hitachi S-4100 Field Emission Scanning Electron (FESEM) microscope has a cold cathode field emission electron gun and secondary and backscattered electron detectors. It is capable of operating at accelerating voltage from $0.5 \mathrm{keV}$ to $30 \mathrm{keV}$. Operation at low voltages allows it to image biological materials and nonconductive, uncoated specimens with minimal charging. However, improved resolution 15 can be obtained by coating the samples. During the early stages, all samples were studied in an uncoated state in the ESEM, because many of the putative nanofossils of ALH84001 have been dismissed as coating artifacts. After it was clearly established that large filamentous trichomic prokaryotic microfossils were found embedded in the freshly fractured surfaces of uncoated meteorite samples and could not be dismissed as coating artifacts, many of the samples were then coated with $5 \mathrm{~nm}$ of Osmium. The resolution limit of the Hitachi S-4100 FESEM is $1.5 \mathrm{~nm}$ at $30 \mathrm{keV}$ and the magnification range is $20 \mathrm{X}$ to $300000 \mathrm{X}$. The minimum electron probe diameter of the Kevex EDS system is approximately 500 angstroms. The investigations of the recent and fossil cyanobacteria from environmental samples, pure cultures, terrestrial rocks, Vostok ice 25 and carbonaceous meteorites were typically carried out with an accelerating voltage of $15 \mathrm{keV}$. However, in order to obtain more accurate EDS data from the lighter elements ( $\mathrm{C}$ and $\mathrm{N}$ ) and to minimize spectral contamination effects from the meteorite rock matrix substrate when analyzing very small microorganisms or thin, electron transparent

Comets, carbonaceous meteorites, and the origin of the biosphere
R. B. Hoover

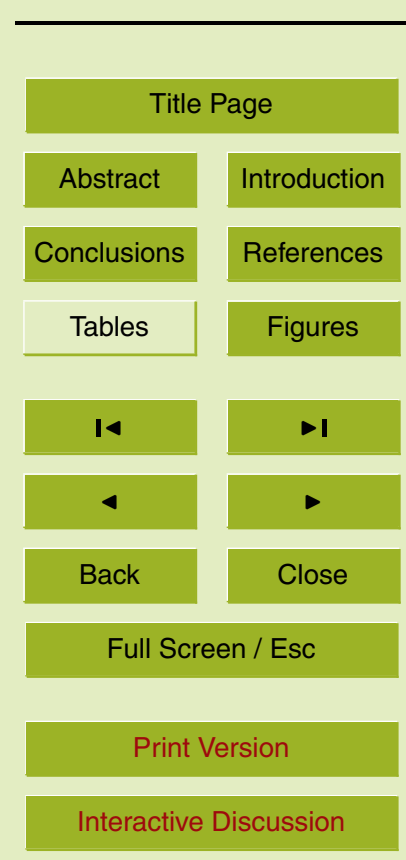


sheaths, the spectral data was sometimes acquired at $11 \mathrm{keV}$ or $5 \mathrm{keV}$ with slightly degraded spatial resolution. In both the ESEM and the FESEM instruments the images were recorded digitally (4Pi Analysis system) with up to $4096 \times 4096$ pixel resolution and 12 bit (4096 grays) digital image depth. EDS data on the elemental abundances 5 were obtained at selected points on the sample or with 2-D x-ray maps for the entire field.

\subsection{Evidence for microfossils in the Murchison CM2 carbonaceous meteorite}

Murchison is a CM2 carbonaceous meteorite that was observed to fall on 28 September 1969. After a bright orange fireball was seen over Victoria, Australia at 10:58 a.m., loud explosions were heard and dozens of black stones fell in a 1 by 10 mile scatter ellipse around the town of Murchison ( $\left.36^{\circ} 37^{\prime} \mathrm{S} ; 145^{\circ} 14^{\prime} \mathrm{E}\right)$. The orientation of the scatter ellipse indicated the meteorite trajectory was from the southeast. Eyewitness observations from several localities allowed Halliday and Mclntosh (1990) to compute the astronomical coordinates of a probable orbit for the Murchison parent body. The probable low inclination orbit with perihelion just inside Earth's orbit indicated the Murchison meteorite had an entry velocity within $15 \%$ of $13 \mathrm{~km} / \mathrm{s}$ and aphelion of $3 \mathrm{AU}$. Values appropriate to the median for meteorite falls and peak concentration of $\mathrm{C}$-type asteroids yielded a derived perihelion between $992 \mathrm{AU}$ and $1.002 \mathrm{AU}$. Seargent (1990) noted the similarity of this orbit with periodic Comet Finlay and to the C-type Apollo asteroid 201979 VA and considered the possibility that the Murchison parent body may have been a comet. He suggested that the Murchison meteorite might have formed as a large boulder "the cap of a pedestal" whose stem slowly eroded away through sustained cometary activity".

Figure 4 is a Field Emission Scanning Electron Microscope image of a well25 preserved microfossil of a filamentous trichomic prokaryote found embedded in a freshly fractured interior surface of the Murchison CM2 carbonaceous meteorite Short trichome segments interpreted as hormogonia $(\mathrm{H})$ are seen in the lower left of the image where they have emerged from the long hollow filament. The hollow sheath is

BGD

3, 23-70, 2006

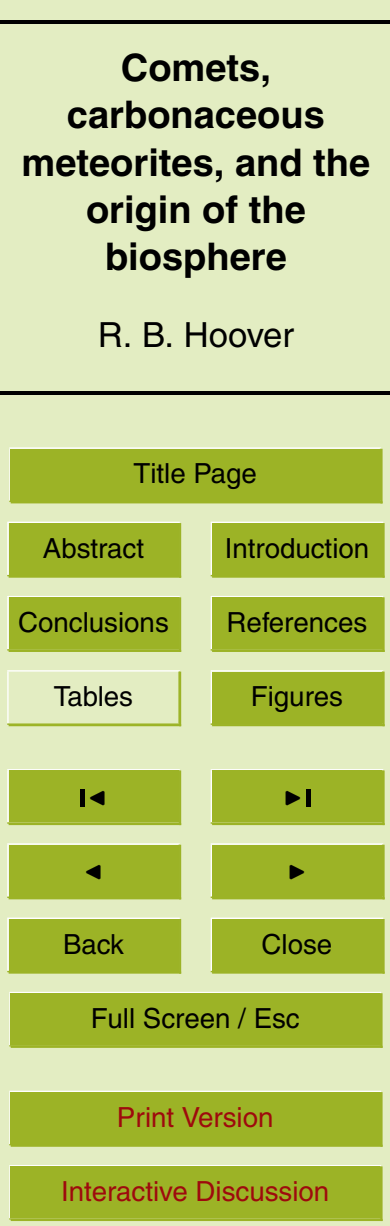

EGU 
broken and can be seen to become a flattened sheath that is embedded in the rock matrix on the right side of the image. Features that are interpreted as representing cross-wall constrictions $(C)$ are visible in both the emergent hormogonia and in the flattened embedded sheath. The appearance of these constrictions indicate that the 5 cells were most likely cylindrical or barrel-shaped with a diameter of $\sim 2.5-3 \mu \mathrm{m}$ and a length somewhat less than the diameter. Several sub-spherical forms ( 4-5 $\mu \mathrm{m}$ diameter) that may represent akinetes are in proximity to the filament. Since a $16 S$ rRNA sequence analysis could not be carried out on the mineralized remains of this microfossil, it is not possible to determine the precise modern biological affinity. However, 10 these mineralized remains of a hollow trichomal filament with flattened sheath and associated akinetes are consistent in size, detailed morphological characteristics, and reproductive structures with the features known in modern Nostocacean cyanobacteria. The size and characteristics of these remains exhibit strong similarities to the modern species Nostoc calcicola Bréb. ex Bornet et Flahault (1888).

15 5.4. Evidence for microfossils in the Orgueil $\mathrm{Cl} 1$ carbonaceous meteorite

The stones of the Orgueil meteorite fell in a 15-18 km east-west scatter ellipse, crossing the small villages of Nohic and Orgueil (Tarn-et-Garonne), at 8:13 p.m. on the evening of 14 May 1864. Inhabitants of Orgueil and Nohic collected over twenty jet black stones (some exceeding $2 \mathrm{~kg}$ mass) immediately after the fall. Gounelle at 20 al. (2004) used the data of Daubree (1864) to compute the orbital parameters of the Orgueil parent body and obtained a semi-axis of 2.4-13 AU with an eccentricity of 0.59-0.93. This result is consistent with the Apollo Asteroid Orbits and the Jupiter family of comets. Lodders and Osborne (1999) considered the mineralogy and chemistry of $\mathrm{Cl}$ and $\mathrm{CM}$ meteorites chondrites and suggested that they represent fragments of 25 cometary nuclei that have evolved into near Earth asteroids after their volatiles were depleted. Ehrenfreund et al. (2001) compared the compositions of the amino acids of the Orgueil and Ivuna CI meteorites with those of the Murchison and Murray CM carbonaceous chondrites and concluded that these groups of meteorites probably originated

BGD

3, 23-70, 2006

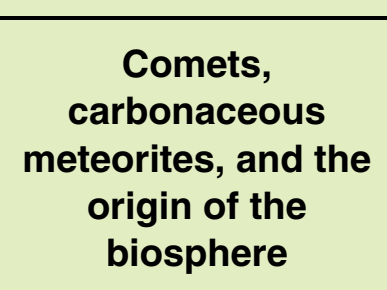

R. B. Hoover

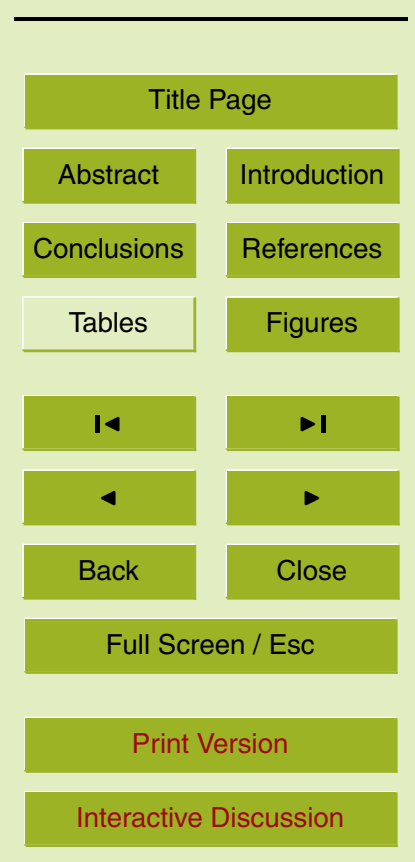

EGU 
from different parent bodies. They also suggest that an extinct comet is the probable parent body for the $\mathrm{Cl}$ carbonaceous chondrites. If the $\mathrm{Cl}$ chondrites are the remains of extinct comets, with most volatiles removed, then the evidence of aqueous alteration (and indigenous microfossils of filamentous prokaryotes and mats) in the $\mathrm{Cl}$ type me5 teorites may also be interpreted as providing evidence for the existence of comets of liquid water and microorganisms on comets (Hoover et al., 1986, 2004a, b; Hoover and Pikuta, 2004).

The initial chemical analyses of the Orgueil meteorite were carried out by Cloez and Pisani in 1864 shortly after the stones were collected. Cloez (1864a, b) conducted the 10 first detailed chemical analysis of the Orgueil stones and found them to be soft, black and friable and to contain $5.30 \%$ water soluble salts. He reported that the meteorite contained magnetite, silicic acid, $5.92 \%$ carbon, and a variety of evaporite minerals and salts - "ammonium and chlorine salt, potassium chloride; sodium chloride, magnesium sulfate, and calcium sulfate." The meteorite was found to be composed of a soft, black, extremely friable material, with ammonium salts, humic substances, magnetite, and silicic acid. Pisani (1864) concluded that the Orgueil silicate minerals are more properly designated serpentine rather than peridotite. A total weight of more than $13 \mathrm{~kg}$ of this extremely fragile, low-density meteorite was recovered. Leymeri (1864a) described the clay-like character he observed as he used a knife to cut into one Orgueil stone immediately after the fall - "The knife cut creates smooth and shiny surfaces which is an indication of a fine, paste-like matter." One of the meteorites landed on hay in an attic but did not set the hay on fire indicating a moderately low surface temperature. However, the fusion crust was still hot enough to burn the hand of the farmer who saw it fall through the roof and reached to pick it up (Leymeri, 1864b). The presence of frost on some of the stones indicated that the interior of the meteorite stones remained cold as the meteorite passed quickly through the atmosphere and ablative cooling carried away the heat.

The Orgueil meteorite is a micro-regolith breccia consisting of particulates ranging in size from several nanometers up to a few hundred microns in size. Orgueil is a

BGD

3, 23-70, 2006

\section{Comets, carbonaceous meteorites, and the origin of the biosphere}

R. B. Hoover

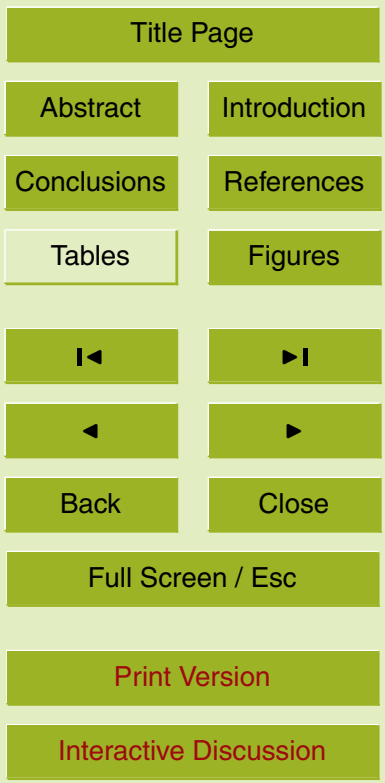


representative of the $\mathrm{Cl}$ class of meteorites. This is one of the most chemically primitive of meteorite classes with near-solar ratios of elemental abundances. However, the volatile abundances represent enrichment that occurred by aqueous alteration rather than primitive solar abundances. The dominant portion of the carbonaceous material of 5 the Orgueil meteorite is in the form of a kerogen-like complex polymeric carbon that is insoluble in water and is similar to peat or lignite coal. Boström and Fredriksson (1966) described Orgueil as a bituminous clay with a breccia structure and clastic texture. They concluded there were three main stages of mineral formation:

1. Early hot stage with minerals like troilite that are stable at several hundred degrees centigrade.

2. Middle stage with minerals like chlorite and limonite forming below $170^{\circ} \mathrm{C}$.

3. Late stage with carbonates and sulfates forming below $50^{\circ} \mathrm{C}$.

Tomeoka and Buseck (1988) have examined the matrix mineralogy of the Orgueil C1 carbonaceous chondrite. The dominant Orgueil mineral is Chlorite $(62.6 \%)$ of the clay 15 phyllosilicates mineral group $\left[(\mathrm{Fe}, \mathrm{Mg}, \mathrm{Al})_{6}(\mathrm{Si}, \mathrm{Al})_{4} \mathrm{O}_{10}(\mathrm{OH})_{8}\right]$. Other major Orgueil minerals include 6.7\% Epsomite $\left(\mathrm{MgSO}_{4} 7 \mathrm{H}_{2} \mathrm{O}\right) ; 6 \%$ Magnetite $\left(\mathrm{Fe}_{3} \mathrm{O}_{4}\right) ; 4.6 \%$ Troilite (FeS), 2.9\% gypsum $\left(\mathrm{CaSO}_{4} \mathrm{nH}_{2} \mathrm{O}\right)$ and $2.8 \%$ Breunnerite $(\mathrm{Fe}, \mathrm{Mg}) \mathrm{CO}_{3}$. Fredriksson and Kerridge (1988) have shown that the $\mathrm{Cl}$ chondrites were formed by aqueous activity in the $\mathrm{Cl}$ parent body based on the compositions and morphologies of their 20 magnesium sulfates, nickel and sodium sulfates, dolomites, breunnerites and calcium carbonates. Magnesium sulfates are dominant minerals in the meteorite and they often occur in veins that were deposited during an extended period of impact brecciation and leaching (Richardson, 1978). The meteorite matrix is a heterogeneous mixture of predominantly ferrihydrite (a poorly crystallized ferric hydroxide containing sulfur and nitrogen), inter-grown with phyllosilicates, serpentine, and saponite produced through aqueous alteration, and lesser amounts of magnetite and sulfides. Orgueil contains presolar grains of graphite, diamond, corundum, silicon carbide and Fe-Ni-sulfide. Al-

BGD

3, 23-70, 2006

\section{Comets, carbonaceous meteorites, and the origin of the biosphere}
R. B. Hoover

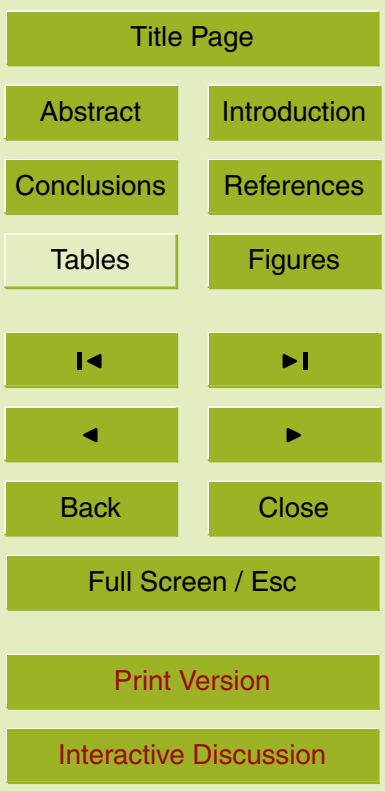


though it is a carbonaceous chondrite, neither Orgueil or any of the other $\mathrm{Cl}$ meteorites show evidence of chondrules.

Figure 5 provides FESEM images of modern cyanobacteria for comparison with the well-preserved and mineralized remains of microfossils of cyanobacteria found in the 5 Orgueil meteorite. This tapered filament of a modern Calothrix sp. (Fig. 5a) from the Little White River, Oregon has a diameter $\sim 0.8 \mu \mathrm{m}$ and a basal heterocyst. It is very similar to the mineralized remains of the complex microstructures found embedded in a freshly fractured interior surface of the Orgueil Cl1 carbonaceous meteorite (Fig. 5b). These mineralized forms are interpreted as indigenous microfossils of a colony of het10 erocystic prokaryotes with tapering filaments (diameter $\sim 1 \mu \mathrm{m}-2.5 \mu \mathrm{m}$ ) and basal heterocysts $(\mathrm{H})$ that are considered to represent morphotypes of the modern filamentous cyanobacteria. These tapered filaments in the Orgueil meteorite also exhibit bulbous structures $\mathrm{H}$, with notably different textures than the associated filament. These microstructures are considered to be similar to basal heterocysts $\mathbf{H}$ on the living Calothrix 15 sp. from the Little White River sample (St. Amand et al., 2005). EDS data taken at the spot designated $\mathbf{F}$ on the filament of the Little White River Calothrix indicated a composition C 69\%; O 9.9\%; P 8\% and N 2.5\%. Figure 5c is the EDS spectrum of the large mineralized filament in the Orgueil meteorite. The EDS spectrum was taken at spot $\mathbf{X}$ on the Orgueil filament shows O 57\%; S 16\%; Mg 15\%; and C 10\% with the elements Nitrogen and Phosphorus below levels of detectability. The magnesium, sulfur and oxygen content are consistent with the interpretation that during the mineralization process the filament was a thin hollow sheath that became infilled with magnesium sulfate that remained behind as an evaporite deposit (possibly epsomite) when the infilling liquid evaporated. Microfossils mineralized by magnesium sulfate are essentially unknown on Earth since epsomite is so water soluble that they would not survive even the slightest rainfall. The total absence of nitrogen and phosphorus in the EDS spectrum clearly indicates that the filament in the Orgueil meteorite does not represent a recent (i.e. post-arrival) biological contaminant. Consequently these remains in the Orgueil $\mathrm{Cl} 1$ carbonaceous meteorite are interpreted as indigenous microfossils repre-

BGD

3, 23-70, 2006

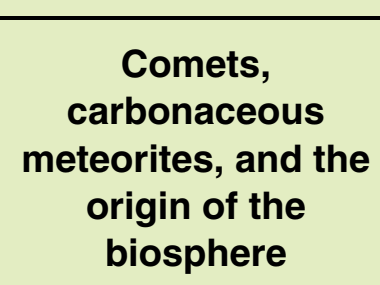

R. B. Hoover

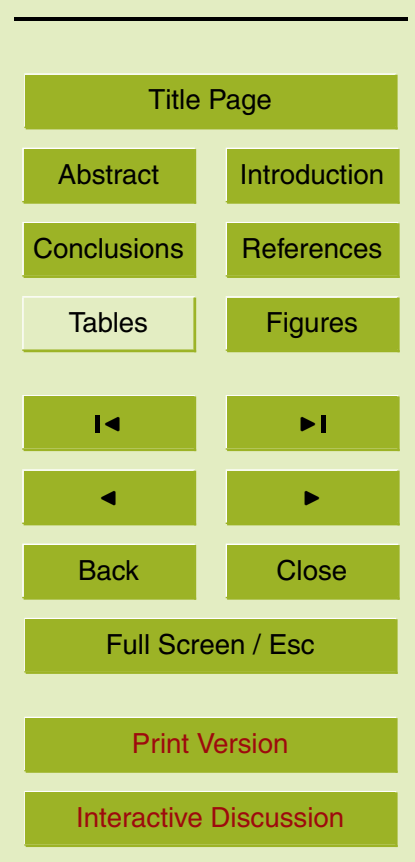


senting morphotypes of a colony of heterocystic filamentous cyanobacteria similar to the modern genus Calothrix.

Cloez (1864a) observed that the Orgueil meteorite disintegrated into fine dust when brought into contact with liquid water - "When the Orgueil meteorite comes in contact 5 with cold water, it completely disintegrates. The meteorite is dispersed into fine particulates which remain in suspension for a long time and which pass through coarser filters. Disintegration in water is the result of the dissolution of salts, which are abundant enough in the stone to act as a cementing agent." He concluded that the rapid disintegration of the stones when immersed in water indicated that the Orgueil meteorites 10 were composed of minute particulates cemented together by water soluble evaporite minerals, such as magnesium sulfate (epsomite).

This important observation was confirmed at NASA/MSFC in July 2005. When small samples of the Orgueil meteorite were exposed to sterile water at $20^{\circ} \mathrm{C}$ (passed through a $0.2 \mu \mathrm{m}$ filter) they totally disintegrated into tiny particulates within one to three minutes after the initial exposure. This is a significant result from the point of view of the possibility of post-arrival contamination of the Orgueil stones by filamentous trichomic prokaryotic microorganisms such as cyanobacteria. These tests make it absolutely clear that the Orgueil stones have not been exposed to liquid water since they entered the Earth's atmosphere. Although very small cryptoendolithic cocoidal cyanobacteria can live in 20 water films between sand grains, the large filamentous cyanobacteria and other trichomic prokaryotic microorganisms require liquid water in order to grow. In addition, liquid water and a water-solid interface are needed for the formation of cyanobacterial mats. Consequently, the mineralized remains of the filamentous trichomic prokaryotic microorganisms and mats found in freshly fractured interior surfaces of the Orgueil $\mathrm{Cl}$ 25 meteorite matrix could not have resulted from contamination by post-arrival biological materials. EDS analysis reveals that many of the microfossils in the Orgueil meteorite are rich in magnesium sulfate and deficient in nitrogen and phosphorus, which provides compelling evidence that the remains are closely associated with the meteorite mineral matrix and do not represent recent contaminants.

BGD

3, 23-70, 2006
Comets, carbonaceous meteorites, and the origin of the biosphere

R. B. Hoover

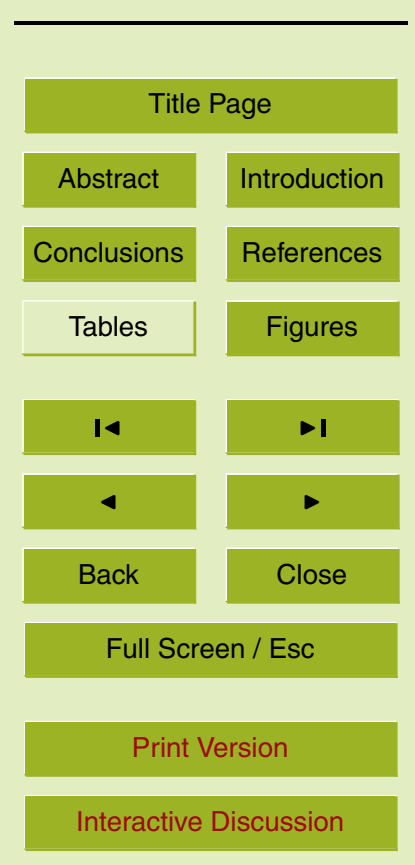


It is important to note that cyanobacteria and sulfur-bacteria that form mats are typically benthic, implying pools of liquid water and a mineral substrate. Cyanobacteria are photoautotrophs and therefore they are not logical candidates for microbial contaminants found in the interior of the jet-black rock matrix of the carbonaceous meteorites.

5 Figure $6 a$ is an image of trichomic cells emerging from a multiseriate filament with parallel trichomes and Fig. $6 \mathrm{~b}$ is the EDS spectrum of the smaller emergent cell showing the strong magnesium and sulfur components and the absence of nitrogen and phosphorus. Figure $6 \mathrm{c}$ is a FESEM image of the mineralized remains of a highly complex prokaryotic mat embedded in the mineral matrix of the Orgueil meteorite. The 10 filamentous forms seen are consistent in both size and morphology to the filaments of components of the well known modern Microcoleus mat communities and fibrils of degraded sheath material.

The detection of microfossil remains that seem to be restricted to the components of trichomic prokaryotic mats (dominated by cyanobacteria and sulfate-reducing bac15 teria) in carbonaceous meteorites is extremely interesting. During the research carried out over the past decade, not a singly recognizable eukaryotic microorganism has been detected in any of the meteorite samples investigated. The cyanobacteria, sulfurand sulfate-reducing bacteria, photosynthetic purple sulfur bacteria, and archaea are the most ancient life forms known on Earth. Microbial life seems to have first appeared on Earth in the Hadean $(>3.5 \mathrm{Ga}$ ) and the few Achaean stromatolites known suggest that mat building cyanobacteria and sulfur-bacteria have been present for at least 3.0-3.5 Ga. The earliest microorganisms may have respired $\mathrm{H}_{2} \mathrm{~S}$ and therefore sulfur probably played a far more important biogenic role during this period. Photosynthetic microorganisms began to flourish by $2.7-2.3 \mathrm{Ga}$ and were primarily responsible
BGD

3, 23-70, 2006

\section{Comets, carbonaceous meteorites, and the origin of the biosphere}

R. B. Hoover

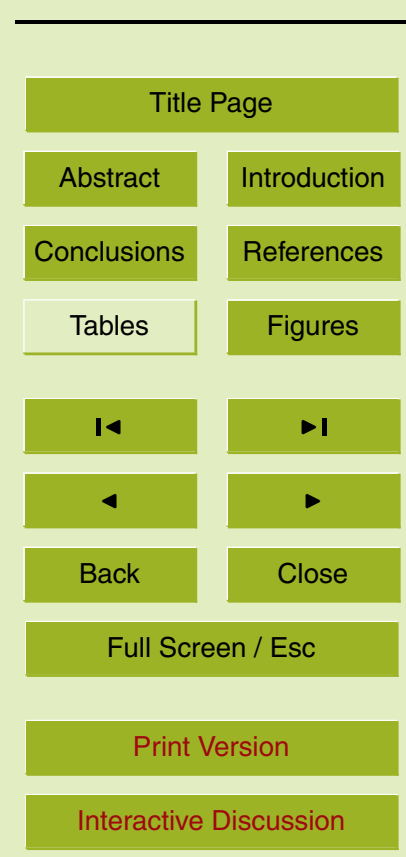




\section{Conclusions}

Comets, meteorites, and interstellar dust played a significant role in the origin and evolution of the biosphere via the delivery of water, organics and prebiotic chemicals to Earth during the Hadean Eon. Recent investigations of microbial extremophiles from 5 deep marine sediments, crustal rocks and polar ice sheets have invalidated many long held paradigms and established that the biosphere is far more extensive than previously recognized. Bacteria, archaea and eukarya thrive in the sulfur rich fluids of deep sea hydrothermal vents, and prokaryotic extremophiles live in hot deep crustal basalts and granites, acidic fumaroles and geysers and alkaline hydrothermal vents. Microbial mophiles also inhabit cold marine sediments, clathrate ices, permafrost and the deep polar ice sheet. Space observations have shown that water is the primary volatile of the comet nucleus, which is encased within extremely low albedo (0.03) black crust that can reach temperatures as high as $400 \mathrm{~K}$ at perihelion. Images of impact craters, cliffs, pinnacles, outbursts and jets on several comets suggest the crust is thicker and might episodically sustain sufficient pressures to allow localized regions of liquid water and brines to form near perihelion. These results indicate that the Whipple "dirty snowball" paradigm may require revision. Since life exists on Earth wherever there is energy, organics, and liquid water, the possibility of liquid water on comets strengthens the possibility that microbial life might be present on some comets. The similarity of the $\mathrm{D} / \mathrm{H}$ ratio, albedo, and chemical compositions of $\mathrm{Cl}$ carbonaceous chondrites and comets supports the hypothesis that the $\mathrm{Cl}$ meteorites may be remnants of extinct comet nuclei with most volatiles removed. Comets and carbonaceous meteorites have been found to contain complex organic chemicals, amino acids, macromolecules, and kerogen-like biopolymers and they may have played a crucial role in the delivery of bombardment.

Field Emission Scanning Electron Microscopy investigations have revealed the existence of a complex suite of indigenous microfossils of morphotypes of cyanobacteria

BGD

3, 23-70, 2006

\section{Comets, carbonaceous meteorites, and the origin of the biosphere}

R. B. Hoover

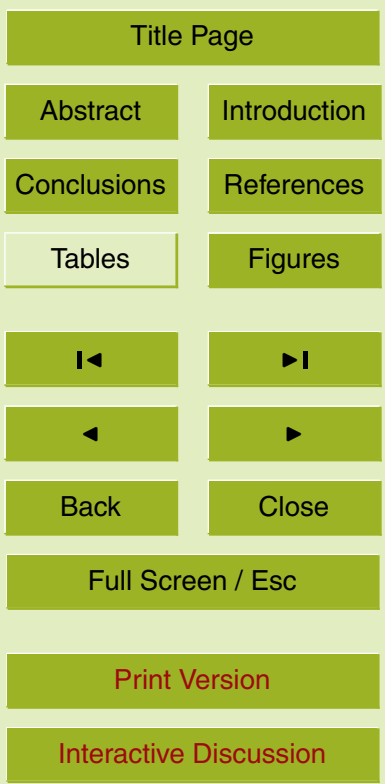


in the $\mathrm{Cl}$ and $\mathrm{CM}$ carbonaceous meteorites. These large forms exhibit complex and differentiated microstructures that are consistent in size and morphology with known filamentous trichomic prokaryotes, cyanobacteria, and cyanobacterial mats. Energy Dispersive X-ray Spectroscopy (EDS) data reveals the absence the biogenic elements 5 nitrogen and phosphorus in the meteorite filaments, which constitutes evidence that the filaments are not recent microbial contaminants and they are interpreted as the mineralized remains of indigenous microfossils in the $\mathrm{Cl}$ and $\mathrm{CM}$ carbonaceous meteorites. The presence of microfossils in carbonaceous meteorites suggests that the fundamental paradigm that life originated endogenously in the primitive oceans of early 10 Earth may require careful reconsideration.

Acknowledgements. I want to thank G. Jerman and J. Coston of NASA/MSFC for Electron Microscopy support during this research and A. Yu. Rozanov of the Institute of Paleontology, RAS and S. Abyzov, Academician Georgy Zavarzin and L. M. Gerasimenko of the Institute of Microbiology, Russian Academy of Science, E. V. Pikuta of NSSTC, and N. C. Wickramasinghe 15 and $\mathrm{M}$. Wallis of the University of Cardiff for many helpful discussions. I am deeply grateful for the meteorite samples provided for this research and want to thank: W. Birch, Victoria Museum, Melbourne, Australia (Murchison); P. Sipiera, Dupont Meteorite Collection \& Planetary Studies Foundation, Chicago (Orgueil, Ivuna); M. Rossignol-Strick (Orgueil) and C. Perron, Musée Nationale d'Histoire Naturelle, Paris (Orgueil).

\section{References}

Abyzov, S. S.: Microorganisms in the Antarctic ice, in: Antarctic Microbiology, edited by: Friedman, E. I., Wiley-Liss, Inc. N.Y., 265-296, 1993.

Abyzov, S. S., Mitskevitch, I. N. Puglozova, M. N., Barkov, N. I., Lipenkov, V. Ya., Bobin, N. E., Koudryashov, B. B., and Pashkevich, V. M.: Long-term conservation of viable microorganisms in ice sheet of Central Antarctica, in: Instruments, Methods, and Missions for Astrobiology, edited by: Hoover, R. B., Proc. SPIE, 3441, 1998.

Abyzov, S. S., Hoover, R. B., Imura, S., Mitskevich, I. N., Naganuma, T., Poglazova, M. N., and Ivanov, M. V.: Use of different methods for discovery of ice-entrapped microorganisms in

BGD

3, 23-70, 2006

\section{Comets, carbonaceous meteorites, and the origin of the biosphere}

R. B. Hoover

\section{Title Page}

Abstract Introduction

Conclusions References

Tables Figures

14

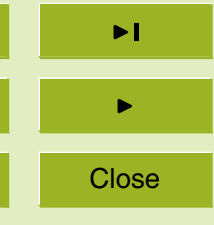

Full Screen / Esc

Print Version

Interactive Discussion 
ancient layers of the Antarctic glacier, Advances in Space Research, Cospar 33, 1222-1230, 2004.

Abyzov, S. S., Gerasimenko, L. M., Hoover, R. B., Mitskevich, I. N., Mulyukin, A. L., Poglazova,

M. N., and Rozanov, A. Yu.: Microbiological methodology in astrobiology, in: Astrobiology and Planetary Missions, edited by: Hoover, R. B., Levin, G. V., Rozanov, A. Yu., and Gladstone, G. R., Proc. SPIE, 5906, 79-95, 2005.

A'Hearn, M. F., Mastrodemos, N., Farnham, T. L., Sunshine, J. M., Belton, M. J. S., Owen, W. M., and Deep Impact Team: Pre-impact outbursts by comet Tempel 1, 37th DPS Meeting, 49 September 2005 Session 43 Deep Impact A, http://www.aas.org/publications/baas/v37n3/ dps2005/683.htm, 2005a.

A'Hearn, M. F., Belton, M. J. S., Delamere, W. A., Kissel, J., Klaasen, K. P., McFadden, L. A., Meech, K. J., Melosh, H. J., Schultz, P. H., Sunshine, J. M., Thomas, P. C., Veverka, J., Yeomans, D. K., Baca, M. W., Busko, I., Crockett, C. J., Collins, S. M., Desnoyer, M., Eberhardy, C. A., Ernst, C. M., Farnham, T. L., Feaga, L., Groussin, O., Hampton, D., Ipatov, S. I., Li, J.-Y., Lindler, D., Lisse, C. M., Mastrodemos, N., Owen Jr., W. M., Richardson, J. E., Wellnitz, D. D., and White, R. L.: Deep Impact: Excavating comet Tempel 1, Science, 130, 258-264, 2005b.

Amy, P. S. and Haldeman, D. S. (Eds.): The Microbiology of the Terrestrial Deep Subsurface, CRC Press, New York, 1-356, 1997.

Anders, E. and Fitch, F.: Search for organized elements in carbonaceous chondrites, Science, 138, 1392-1399, 1962.

Anders, E., Dufresne, E. R., Hayatsu, R., Cavaille, A., Dufresne, A., and Fitch, F. W.: Contaminated meteorite, Science, 146, 1157-1161, 1964.

Arrhenius, S.: The propagation of life in space, Die Umschau, 7, 481, 1903.

Bornet, C. and Flahault, E.: Revision des Nostocacées Hétérocystées. IV, Ann. Sci. Nat. Bot. Ser., 7, 177-262, 1888.

Boström, K. and Fredriksson, K.: Surface conditions of the Orgueil parent meteorite body as indicated by mineral associations, Smithson. Misc. Coll., 151, 1-39, 1966.

Brock, T. D. and Freeze, H.: Thermus aquaticus gen. n. and sp. n. a non-sporulating extreme thermophile, J. Bacteriol., 98, 289-297, 1969.

Cameron, A. G. W.: Origin of the Solar System, Ann. Rev. Astron. Astrophys., 26, 441-472, 1988.

Cameron, A. G. W. and Benz, W.: Possible scenarios resulting from the giant impact, Proc.

3, 23-70, 2006

Comets, carbonaceous meteorites, and the origin of the biosphere

R. B. Hoover

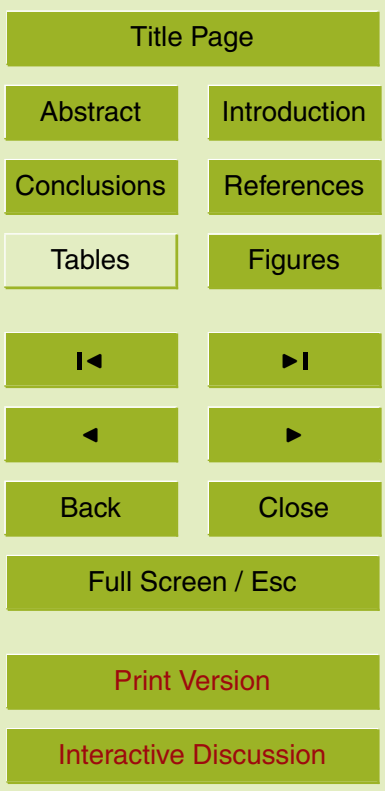


Lunar Planet. Sci. Conf. XX, 715, 1989.

Chamberlin T. C. and Chamberlin, R. T.: Early terrestrial conditions that may have favored organic synthesis, Science, 28, 897-910, 1908.

Chyba, C. F.: Impact delivery and erosion of planetary oceans in the early inner solar system, Nature, 343, 129-133, 1990a.

Chyba, C. F.: Extraterrestrial amino acids and terrestrial life, Nature, 348, 113-114, 1990b.

Chyba, C. F. and Sagan, C.: Comets as a source of prebiotic molecules for the early Earth, in: Comets and the Origin and Evolution of Life, edited by: Thomas, P. J., Chyba, C. F., and McKay, C. P., Springer-Verlag, New York, 147-168, 1997.

Claus, G. and Nagy, B.: A microbiological examination of some carbonaceous chondrites, Nature, 192, 594-596, 1961.

Clayton, R. N. and Mayeda, T. K.: The oxygen isotope record in Murchison and other carbonaceous chondrites, Earth Planet. Sci. Lett., 67, 151-161, 1984.

Cloez, S.: Note sur la composition chimique de la pierre météorique d'Orgueil, Compt. Rend. Acad. Sci., 58, 984-986, 1864a.

Cloez, S.: Analyse chimique de la pierre météorique d'Orgueil, Compt. Rend. Acad. Sci., 59, 37-40, 1864b.

Corliss, J. B., Dymond, J., Gordon, L. I., Edmond, J. M., von Herzen, R. P., Ballard, R. D., Green, K., Williams, D., Bainbridge, A., Crane, K., and van Andel, T. H.: Submarine thermal springs on the Galapagos Rift, Science, 203, 1073-1083, 1979.

Delaye, $L$ and Lazcano, A.: Prebiological evolution and the physics of the origin of life, Phys. of Life Rev., 2, 47-64, 2005.

Daubrée, A.: Note sur les meteorites tombées le 14 mai aux environs d'Orgueil (Tarn-etGaronne), Compt. Rend. Acad. Sci. Paris, 58, 984-984, 1864.

Delsemme, A.: The origin of the atmosphere and of the oceans, in: Comets and the Origin and Evolution of Life, edited by: Thomas, P. J., Chyba, C. F., and McKay, C. P., Springer-Verlag, New York, 54, 1997.

Delsemme, A. H.: The deuterium enrichment observed in recent comets is consistent with the cometary origin of seawater, Planet. Space Sci., 47, 125-131, 1998.

30 Dufresne, E. R. and Anders, E.: On the chemical evolution of the carbonaceous chondrites, Geochim. Cosmochim, Acta, 26, 1085-1114, 1962.

Elvert, M., Suess, E., Greinert, J., and Whiticar, M. J.: Archaea mediating anaerobic methane oxidation in deep-sea sediments at cold seeps of the eastern Aleutian subduction zone,
BGD

3, 23-70, 2006

\section{Comets, carbonaceous meteorites, and the origin of the biosphere}

R. B. Hoover

\section{Title Page}

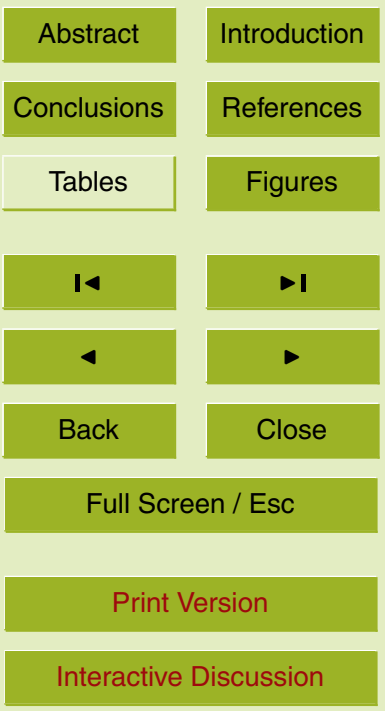


Organic Geochem., 31, 1175-1187, 2000.

Emerich, C., Lamarre, J. M., Moroz, V. I., Combes, M., Sanko, N. F., Nikolsky, Y. V., Rocard, F., Gispert, R., Coron, N., Bibring, J. P., Encrenaz, T., and Crovisier, J.: Temperature and size of the nucleus of Comet P/Halley deduced from IKS infrared Vega 1 measurements, Astron.

$5 \quad$ Astrophys., 187, 839-842, 1987.

Ehrenfreund, P., Glavin, D. P., Botta, O., Cooper, G., and Bada, J.: Extraterrestrial amino acids in Orgueil and Ivuna: Tracing the parent body of $\mathrm{Cl}$ type carbonaceous chondrites, PNAS 98, 2138-2141, 2001.

Fisher, C. R., MacDonald, I. R., Sassen, R., Young, C. M., Macko, S. A., Hourdez, S., Carney, R. S., Joye, S., and McMullin, E.: Methane ice worms: Hesiocaeca methanicola colonizing fossil fuel reserves, Naturwissenschaften, 87, 184-187, 2000.

Fisk, M. R., Storrie-Lombardi, M. C., Douglas, S., McDonald, G. D., Popa, R., and Savoie, C. A.: Evidence of biological activity in Hawaiian subsurface basalts, Geochem. Geophys. and Geosys., 4, 1-24, 2003.

15 Fitch, F. W., Schwarz, H. P., and Anders, E.: Organized elements in carbonaceous chondrites, Nature 193, 1123-125, 1962.

Fitch, F. W. and Anders, E.: Organized element: possible identification in Orgueil meteorite, Science, 140, 1097-1099, 1963a.

Fitch, F. W. and Anders, E.: Observations of the nature of "organized elements" in carbonaceous chondrites, Ann. N. Y. Acad. Sci., 108, 495-513, 1963b.

Frederickson, J. K., Garland, T. R., Hicks, R. J., Thomas, J., Li, S., and McFadden, K.: Lithotrophic and heterotrophic bacteria in deep subsurface sediments and their relation to sediment properties, Geomicrobiol. J., 7, 53-66, 1989.

Frederickson, J. K. and Onstott, T. C.: Microbes deep inside the Earth, Scientific American, 275, 68-73, 1996.

Fredriksson, K. and Kerridge, J. F.: Carbonates and sulfates in Cl Chondrites: Formation by aqueous activity on the parent body, Meteoritics, 23, 35-44, 1988.

Friedmann, I.: Permafrost as microbial habitat, in: Viable Microorganisms in Permafrost, edited by: Gilichinsky, D., Russian Academy of Sciences, 21-26, 1994.

30 Gerasimenko, L. M., Hoover, R. B., Rozanov, A. Yu., Zhegallo, E. A., and Zhmur, S. I.: Bacterial paleontology and studies of carbonaceous chondrites, Paleontological Journal, 33, 439-459, 1999.

Gilichinsky, D. A., Vorobyova, E. A., Erokhina, L. G., Fedorov-Davydov, D. G., and
BGD

3, 23-70, 2006

Comets, carbonaceous meteorites, and the origin of the biosphere

R. B. Hoover

\section{Title Page}

Abstract

Introduction

Conclusions References

Tables Figures

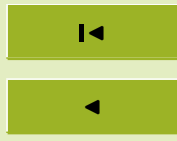

Back

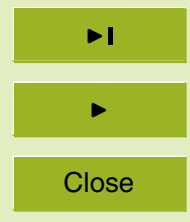

Full Screen / Esc

Print Version

Interactive Discussion 
Chaikovskaya, N. R.: Long-term preservation of microbial ecosystems in permafrost, Adv. Space Res. 12, 255-263, 1992.

Gilichinsky, D., Wegener, S., and Vishnivetskaya, T.: Permafrost microbiology, in: Permafrost and Periglacial Processes, 2, 281-291, 1995.

5 Gilichinsky, D. A.: Permafrost as a microbial habitat: extreme for the Earth, favorable in space, in: Instruments, Methods, and Missions for the Investigation of Extraterrestrial Microorganisms, edited by: Hoover, R. B., Proc. SPIE, 3111, 472-481, 1997.

Gold, T.: The deep, hot biosphere, Proc. Natl. Acad. Sci. USA, 89, 6045—6049, 1992.

Gooday, A. J., Holzmann, M., Guiard, J., Cornelius, N., and Pawlowski, J.: A new monothalamous foraminiferan from 1000 to $6300 \mathrm{~m}$ water depth in the Weddell Sea: morphological and molecular characterization, in: Deep Sea Research Part II: Topical Studies in Oceanography, 51, 1603-1616, 2004.

Gounelle, M., Spurny, P., and Bland, P. A.: The orbit of the Orgueil meteorite from historical records, Meteorit. Planet. Sci., 39 (Suppl.), A45, 2004.

15 Ghiorse, W. C. and Wilson, J. T.: Microbial ecology of the terrestrial subsurface, Adv. Appl. Microbiol., 33, 107-172, 1988.

Halliday, I. A. and Mclntosh, B. A.: Orbit of the Murchison meteorite, Meteoritics, 25, 339-340, 1990.

Hahn, G. and Bailey, M. E.: Rapid dynamical evolution of giant comet Chiron, Nature, 348, 132-136, 1990.

Hay, R. J.: Preservation of cell stock cultures in liquid nitrogen, TCA Manual, 4, 787-790, 1978. Heckly, R. J.: Preservation of microorganisms, Adv. in Appl. Microbiol., 24, 1-53, 1978.

Holland, H. D.: The Chemical Evolution of the Atmosphere and Oceans, Princeton Univ. Press, Princeton, 1984.

Hoover, R. B., Hoyle, F., Wickramasinghe, N. C., Hoover, M. J., and Al-Mufti, S.: Diatoms on Earth, comets, Europa and in interstellar space, Earth, Moon, and Planets, 35, 19-45, 1986.

Hoover, R. B.: Meteorites, microfossils and exobiology, in: Instruments, Methods, and Missions for the Investigation of Extraterrestrial Microorganisms, edited by: Hoover, R. B., Proc. SPIE, 3111, 115-136, 1997.

30 Hoover, R. B., Rozanov, A. Yu., Zhmur, S. I., and Gorlenko, V. M.: Further evidence of microfossils in carbonaceous chondrites, in: Instruments, Methods and Missions for Astrobiology, edited by: Hoover, R. B., Proc. SPIE 3441, 203-216, 1998.

Hoover, R. B. and Gilichinsky, D.: Significance to Astrobiology of microorganisms in permafrost

3, 23-70, 2006

Comets, carbonaceous meteorites, and the origin of the biosphere

R. B. Hoover

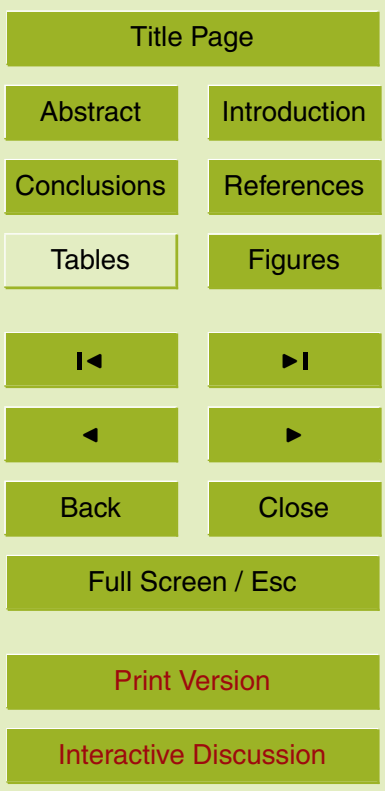


and ice, in: Permafrost Response on Economic Development, Environmental Security and Natural Resource Potential, NATO-ARW held in NOVOSIBIRSK, SIBERIA, 12-16 November 1998, edited by: Paepe, R., Klewer Publishing, New York, 553-580, 2001.

Hoover, R. B. and Rozanov, A. Yu.: Microfossils, biominerals and chemical biomarkers in Meteorites, in: Instruments Methods and Missions for Astrobiology VI, edited by: Hoover, R. B., Rozanov, A. Yu., and Lipps, J. H., Proc. SPIE 4939, 10-27, 2003.

Hoover, R. B., Jerman, G., Rozanov, A. Yu., and Davies, P. C. W.: Biomarkers and microfossils in the Murchison, Tagish Lake, and Rainbow Meteorites, in: Instruments Methods and Missions for Astrobiology V, edited by: Hoover, R. B., Rozanov, A. Yu., and Paepe, R. R., Proc. SPIE 4859, 15-31, 2003.

Hoover, R. B. and Pikuta, E. V.: Microorganisms on comets, Europa, and the polar ice caps of Mars, in: Instruments Methods and Missions for Astrobiology VII, edited by: Hoover, R. B., Levin, G. V., and Rozanov, A. Yu., Proc. SPIE 5163, 191-202, 2004.

Hoover, R. B., Jerman, G., Rozanov, A. Yu., and Sipiera, P. P.: Indigenous microfossils in 15 carbonaceous meteorites, in: Instruments Methods and Missions for Astrobiology VIII, edited by: Hoover, R. B., Levin, G. V., and Rozanov, A. Yu., Proc. SPIE 5555, 1-17, 2004a.

Hoover, R. B., Pikuta, E. V., Wickramasinghe, N. C., Wallis, M. K., and Sheldon, R. B.: Astrobiology of Comets, in: Instruments Methods and Missions for Astrobiology VIII, edited by: Hoover, R. B., Levin, G. V., and Rozanov, A. Yu., Proc. SPIE 5555, 93-106, 2004b.

Hoover, R. B.: Microfossils, biominerals, and chemical biomarkers in meteorites, in: Perspectives in Astrobiology, Vol. 366, NATO Science Series: Life and Behavioural Sciences, edited by: Hoover, R. B., Paepe, R. R., and Rozanov, A. Yu., IOS Press, Amsterdam, Netherlands, 43-65, 2005.

Hoshai, T.: Seasonal change of ice communities in the sea ice near Syowa Station, Antarctica, in: Polar Oceans, edited by: Dunbar, M. J., Canada: Arctic Institute of North America, 307317, 1977.

Hoyle, F. and Wickramasinghe, N. C.: Astronomical Origins of Life - Steps Towards Panspermia, Klewer Academic Publishers, 1-381, 2000.

Kato, C. I., Li, Y., Nakamura, Y., Nogi, J., Tamaoka, N., and Horikoshi, K.: Biodiversity of the world's deepest sediment of the Mariana Trench, at a depth of $11000 \mathrm{~m}$ and isolation of hyperbarophilic bacteria from the same sediment, JAMSTEC J. Deep Sea Res., 13, 119130, 1997.

Kerridge, J. F.: Mineralogy and genesis of the carbonaceous meteorites, in: Mantles of the
BGD

3, 23-70, 2006

\section{Comets, carbonaceous meteorites, and the origin of the biosphere}
R. B. Hoover

\section{Title Page}

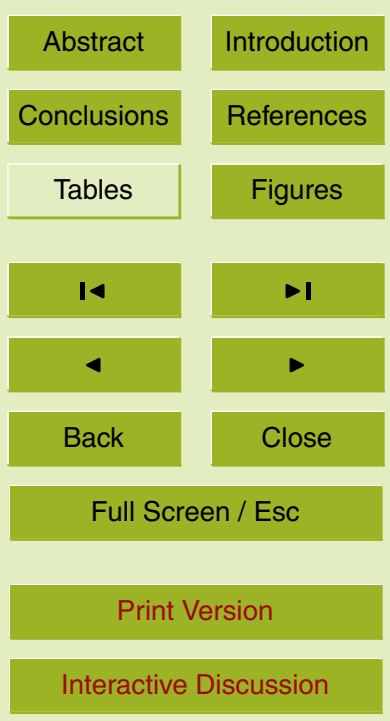


Terrestrial Planets, edited by: Runcorn, S. K., Interscience, Wiley \& Sons, 35-47, 1967.

Kuznetsov, A. I., Ivanov, M. V., and Lyalikova, N. K.: Introduction to Geological Microbiology, (English edition), McGraw Hill, New York, NY, 1963.

Kvenvolden, K. A.: Gas hydrates - geological perspective and global change, Rev. Geophys., 31, 173-187, 1993.

Lanoil, B. D., Sassen, R., La Duc, M. T., Sweet, S. T., and Nealson, K. H.: Bacteria and archaea physically associated with Gulf of Mexico gas hydrates, Appl. Environ. Microbiol., 67, 51435153, 2001.

Le Gall, J.: A new species of Desulfovibrio, J. Bacteriol., 86, 1120, 1963.

10 Leymeri, M.: Written communication with Mr. Daubrée, Compt. Rend. Acad. Sci., 58, 982-989, $1864 a$.

Leymeri, M.: Written communication with Mr. Daubrée, Compt. Rend. Acad. Sci., 58, 1072, $1864 \mathrm{~b}$.

Lodders, K. and Osborne, R.: Perspectives on the comet-asteroid-meteorite link, Space Sci. 15 Rev., 90, 289-297, 1999.

Lysnes, K., Thorseth, I. H., Steinsbu, B. O., Øvreås, L., Torsvik, T., and Pedersen, R. B.: Microbial community diversity in seafloor basalt from the Arctic spreading ridges, FEMS Microbiology Ecology, 50, 213-230, 2004.

McKay, D. S., Gibson Jr., E. K., Thomas-Keprta, K. L., Vali, H., Romanek, C. S., Clemett, S. J., Chillier, X. D. F., Maechling, C. R., and Zare, R. N.: Search for past life on Mars: Possible relic biogenic activity in Martian meteorite ALH84001, Science, 273, 924-930, 1996.

Miller, S. L.: The mechanism of synthesis of amino acids by electric discharge, Biochem. Biophys. Acta, 23, 480-487, 1957.

Miller, S. L. and Urey, H. C.: Organic compound synthesis on the primitive Earth, Science, 130, 245-252, 1959.

Miller, S. L. and Orgel, L. E.: The Origins of Life on Earth, (Prentice-Hall, Englewood Cliffs, NJ), 1974.

Miller, S. L. and Bada, J. L.: Submarine hot springs and the Origin of Life, Nature, 334, 609$611,1988$.

30 Nagy, B., Meinschein, W. G., and Hennessy, D. J.: Mass spectroscopic analysis of the Orgueil meteorite: Evidence for biogenic hydrocarbons, Ann. N. Y. Acad. Sci., 93, 25-35, 1961.

Nagy, B.: Carbonaceous Meteorites. Elsevier Scientific Publishing Co., New York, 1-747, 1975. Nealson, K. H. and Stahl, D. A.: Microorganisms and biogeochemical cycles: What can we
BGD

3, 23-70, 2006

Comets, carbonaceous meteorites, and the origin of the biosphere

R. B. Hoover

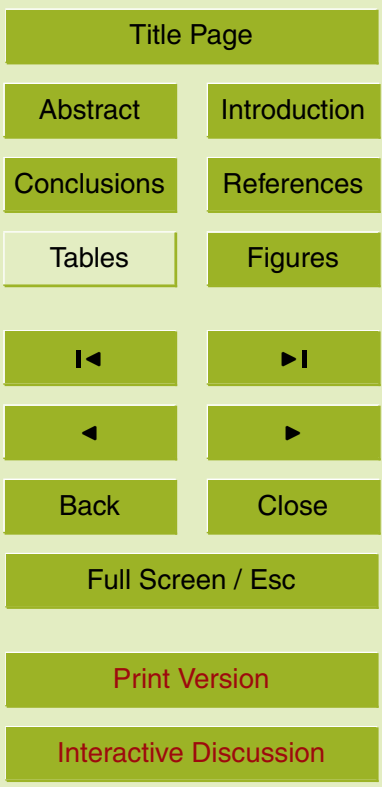


learn from layered microbial communities?, in: Geomicrobiology: Interactions between Microbes and Materials, edited by: Banfield, J. F. and Nealson, K. H., Reviews in Mineralogy, Vol. 35, Mineralogical Society of America, Washington, D.C., 5-34, 1997.

Olson, G. J., Dockins, W. S., and McFeathers, G. A.: Sulfate reducing and methanogenic bacteria from deep aquifers in Montana, Geomicrobiol. J., 2, 327-340, 1981.

Onstott, T. C., Moser, D. P., Pfiffner, S. M., Fredrickson, J. K., Brockman, F. J., Phelps, T. J., White, D. C., Peacock, A., Balkwill, D., Hoover, R., Krumholz, L. R., Borscik, M., Kieft, T. L., and Wilson, R.: Indigenous and contaminant microbes in ultradeep mines, Environ. Microbiol., 5, 1168-1191, 2003.

10 Oort, J. H.: The structure of the cloud of comets surrounding the Solar System, and a hypothesis cncerning its origin, Bull. Astron. Inst. Neth., 11, 91-110, 1950.

Oparin, A.: Proiskhozhdenie Zhizni (Moskovskii Rabochii, Moscow), 1924, (Translated by: Bernal, J. B. and re-printed in: "The Origin of Life" London, Weidenfeld and Nicolson, 1967.) Oparin, A.: The Origin of Life, Macmillan, New York, 1938.

15 Oparin, A.: The Origin of Life, in: The Origin of Life, edited by: Bernal, J. D., Wiedenfield and Nicolson, London, 199-234, 1967.

Oró, J.: Synthesis of adenine from ammonium cyanide, Biochem. Biophys. Res. Comm., 2, 412-417, 1960.

Oró, J.: Comets and the formation of biochemical compounds on the primitive Earth, Nature, 190, 442-443, 1961.

Oró, J. and Lazcano, A.: Comets and the origin and evolution of life, in: Comets and the Origin and Evolution of Life, edited by: Thomas, P. J., Chyba, C. F., and McKay, C. P., SpringerVerlag, New York, 2-27, 1997.

Pedersen, K. and Ekendahl, S.: Distribution and activity of bacteria in deep granitic groundwaters of southern Sweden, Microb. Ecol., 22, 1-14, 1990.

Pikuta, E. V. and Hoover, R. B.: Growth of the facultative anaerobes from Antarctica, Alaska, and Patagonia at low temperatures, in: Instruments Methods and Missions for Astrobiology VIII, edited by: Hoover, R. B., Levin, G. V., and Rozanov, A. Yu., Proc. SPIE 5555, 160-191, 2004.

30 Pikuta, E. V., Marsic, D., Bej, A., Tang, J., Krader, P., and Hoover, R. B.: Carnobacterium pleistocenium sp. nov., a novel psychrotolerant, facultative anaerobe isolated from permafrost of the Fox Tunnel in Alaska, Int. J. Syst. Evol. Microbiol., 55, 473-478, 2005.

Pisani, F.: Etude chimique et analyse de l'aerolithe d'Orgueil, Compt. Rend. Acad. Sci., 59,

\section{Comets, carbonaceous meteorites, and the origin of the biosphere}

R. B. Hoover

\section{Title Page}

Abstract Introduction

Conclusions

Tables References Figures

14

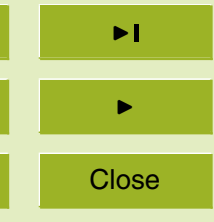

Full Screen / Esc

Print Version

Interactive Discussion 
132-135, 1864.

Richardson, S. M.: Vein formation in the Cl carbonaceous meteorites, Meteoritics, 13, 141-159, 1978.

Rossignol-Strick, M. and Barghoorn, E. S.: Extraterrestrial abiogenic organization of organic matter: The hollow spheres of the Orgueil meteorite, Space Life Sci., 3, 89-107, 1971.

Rossignol-Strick, M., Hoover, R. B., Jerman, G., and Coston, J.: The hollow spheres of the Orgueil meteorite: A re-examination, in: Astrobiology and Planetary Missions, edited by: Hoover, R. B., Levin, G. V., Rozanov, A. Yu., and Gladstone, G. R., Proc. SPIE 5906, 197207, 2005.

10 Rozanov, A. Yu. and Hoover, R. B.: Bacterial paleontology and Astrobiology, in: Instruments Methods and Missions for Astrobiology IV, edited by: Hoover, R. B., Levin, G. V., Paepe, R., and Rozanov, A. Yu., Proc. SPIE 4495, 283-294, 2002.

Sahling, H., Galkin, S. V., Salyuk, A., Grienert, J., Foerstel, H., Piepenburg, D., and Suess, E.: Depth-related structure and ecological significance of cold-seep communities - a case study from the Sea of Okhotsk, Deep Sea Res. I, 50, 1391-1409, 2003.

Schidlowski, M.: A 3800 million-year-old record of life from carbon in sedimentary rocks, Nature, 333, 313-318, 1988.

Schidlowski, M.: Carbon isotopes as biogeochemical recorders of life over $3.8 \mathrm{Ga}$ of Earth history: evolution of a concept, Precambrian Research, 106, 117-134, 2001.

Schippers, A., Neretin, L. N., Kallmeyer, J., Ferdelman, T. G., Cragg, B. A., Parkes, R. J., and Jorgensen, B. B.: Prokaryotic cells of the deep sub-seafloor biosphere identified as living bacteria, Nature, 433, 861-864, 2005.

Seargent, D. A. J.: The Murchison meteorite: Circumstances of its fall, Meteoritics, 25, 341342, 1990.

Sheldon, R. B. and Hoover, R. B.: Evidence for liquid water on comets, in: Astrobiology and Planetary Missions, edited by: Hoover, R. B., Levin G. V, Rozanov, A. Yu., and Gladstone, G. R., Proc. SPIE, 5906, 127-145, 2005.

Shi, T., Reeves, R. H., Gilichinsky, D. A., and Friedmann, E. I.: Characterization of viable bacteria from Siberian permafrost by $16 S$ rDNA sequencing, Microbial Ecol., 33, 169-179, 1997.

Simone, F. P. and Brown, E. M. (Eds.): ATCC Preservation Methods: Freezing and Freeze Drying, American Type Culture Collection, Rockville, Maryland, 1-90, 1991.

Sipiera, P. P. and Hoover, R. B.: Meteorites and microbes: meteorite collection and ice sampling
BGD

3, 23-70, 2006

Comets, carbonaceous meteorites, and the origin of the biosphere

R. B. Hoover

\section{Title Page}

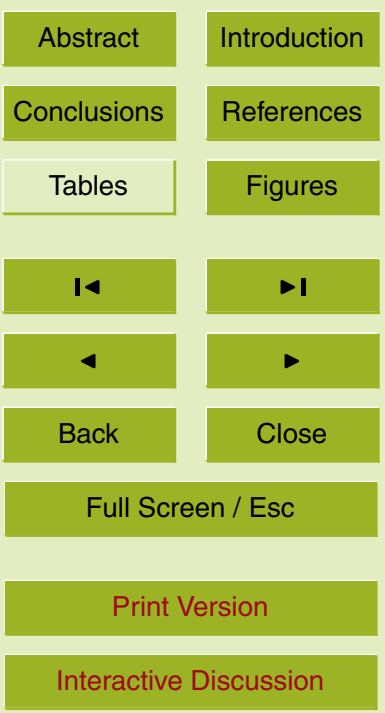


at Patriot Hills, Thiel Mountains, and South Pole, Antarctica, Proc. SPIE 4137, 13-21, 2001.

Soina, V. S. and Vorobyova, E. A.: Preservation of cell structures in permafrost: a model for exobiology, Adv. Space Res., 15, 237-242, 1995.

St. Amand, A., Hoover, R. B., Jerman, G., Coston, Y., and Rozanov, A. Yu.: Morphology and elemental composition of recent and fossil cyanobacteria, in: Astrobiology and Planetary Missions, edited by: Hoover, R. B., Levin, G. V., Rozanov, A. Yu., and Gladstone, G. R., Proc. SPIE, 5906, 19-28, 2005.

Steel, D.: Cometary impacts in the Biosphere, in: Comets and the Origin and Evolution of Life, edited by: Thomas, P. J., Chyba, C. F., and McKay, C. P., Springer-Verlag, New York, 216, 1997.

Stevens, T. O. and McKinley, J. P.: Lithoautotrophic microbial ecosystems in deep basalt aquifers, Science, 270, 450-454, 1995.

Sugita, S., Ootsubo, T., Kadono, T., Honda, M., Sako, S., Miyata, T., Sakon, I., Yamashita, T., Kawakita, H., Fujiwara, H., Fujiyoshi, T., Takato, N., Fuse, T., Watanabe, J., Furusho, R., Hasegawa, S., Kasuga, T., Sekiguchi, T., Kinoshita, D., Meech, K. J., Wooden, D. H., Ip, W. H., and A'Hearn, M. F.: Subaru telescope observations of Deep Impact, Science, 130, 274-277, 2005.

Sykes, M. V. and Walker, R. G.: Cometary dust trails, I. Survey, Icarus, 95, 180-210, 1992.

Tan, W. C. and VanLandingham, S. L.: Electron microscopy of biological-like structures in the Orgueil carbonaceous meteorite, Geophys. J. Roy. Astr. Soc., 12, 237-239, 1967.

Thorseth, I. H., Torsvik, T., Torsvik, V., Daae, F. L., and Pedersen, R. B.: and Keldysh-98 Scientific Party: Diversity of life in ocean floor basalt, Earth and Planet. Sci. Lett., 194, 3137, 2001.

Thomas, P. C., Parker, J. W., McFadden, L. A., Russell, C. T., Stern, S. A., Sykes, M. V., and Young, E. F.: Differentiation of the asteroid Ceres as revealed by its shape, Nature, 437, 224-226, 2005.

Timofeev, W.: Lebensspuren in Meteoriten: Resultate einer microphytologischen Analyse, Grana. Palynol., 4, 92-99, 1963.

Todo, Y., Kitazato, H., Hashimoto, J., and Gooday, A. J.: Simple foraminifera flourish at the ocean's deepest point, Science, 307, 689, 2005.

Tomeoka, K. and Buseck, P. R.: Matrix mineralogy of the Orgueil C1 carbonaceous chondrite, Geochim. Cosmochim. Acta, 52, 1627-1640, 1988.

Tunnicliffe, V.: Hydrothermal-vent communities of the deep sea, American Scientist, 80, 336-
BGD

3, 23-70, 2006

\section{Comets, carbonaceous meteorites, and the origin of the biosphere}

R. B. Hoover

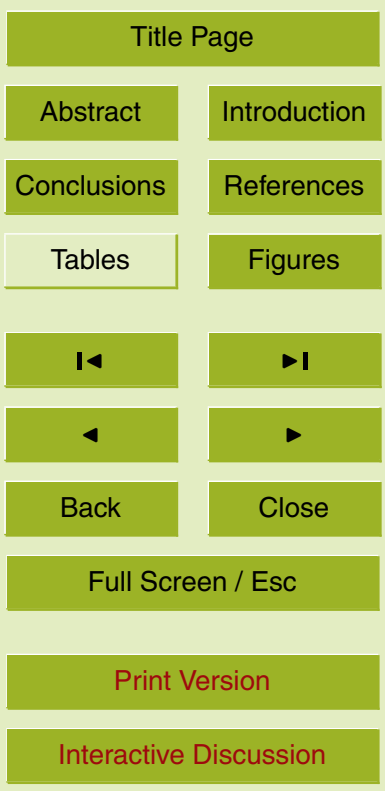


349, 1992.

Urey, H. C.: Biological material in meteorites: A review, Science, 151, 157-166, 1966.

Vernadsky, V. I.: La Géochemie, 1-24, 1924.

Vernadsky, V. I.: Biosfera, Leningrad, Nauka, 1926.

5 Vernadsky, V. I.: The Biosphere (Translation by: Langmuir, D. B., revised and annotated by: McMenamin, M. A. S.), Copernicus, New York, 1-192, 1998.

von Helmholtz, H.: The Origin of the Planetary System, in: Selected Writings of Hermann von Helmholtz, Wesleyan University Press, 284, 1871.

Vorobyova, E. A., Soina, V. S., and Mulukin A. L.: Microorganisms and enzyme activity in permafrost after removal of long-term cold stress, Adv. Space Res., 18, 103-108, 1996.

Wallis, M. K. and Wickramasinghe, N. C.: Structural Evolution of Cometary Surfaces, Space Sci. Rev., 56, 93-97, 1991.

Watson, E. B. and Harrison, T. M.: Zircon thermometer reveals minimum melting conditions on earliest Earth, Science, 308, 841-844, 2005.

15 Wetherill, G. W.: Formation of the Earth, Ann. Rev. Earth Planet. Sci., 18, 205-256, 1990.

Whipple, F. L.: A comet model, I. The acceleration of Comet Enke, Astrophys. J., 111, 134-141, 1950.

Whipple, F. L.: A comet model, II. Physical relations for comets and meteors, Astrophys. J., 113, 464-474, 1951.

20

Whipple, F. L.: On the structure of the cometary nucleus, in: The Moon, Meteorites, and Comets, edited by: Middlehurst, B. M. and Kuiper, G. P., University of Chicago Press, Chicago, 639-664, 1963.

Whitman, W. B., Coleman, D. C., and Wiebe, W. J.: Prokaryotes: The unseen majority, Proc. Natl. Acad. Sci. USA, 95, 6578-6583, 1998.

Wickramasinghe, N. C. and Hoyle, F.: Infrared radiation from Comet Hale-Bopp, Astrophys. Space Sci., 268, 379-381, 1999.

Woese, C. R. and Fox, G. E.: Phylogenetic structure of the Prokaryotic Domain: The Primary Kingdoms, Proc. Natl. Acad. Sci. USA, 74, 5088-5090, 1977.

Zavarzin, G. A.: Bacteria and Composition of Atmosphere, Moscow, Nauka, 1-120, 1984.

30 Zhmur, S. I., Rozanov, A. Yu., and Gorlenko, V. M.: Lithified remnants of microorganisms in carbonaceous chondrites, Geochemistry International, 35, 58-60, 1997.
BGD

3, 23-70, 2006

\section{Comets, carbonaceous meteorites, and the origin of the biosphere}

R. B. Hoover

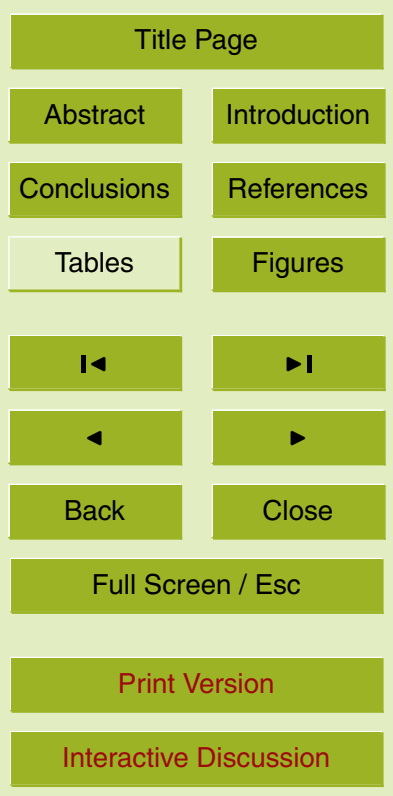




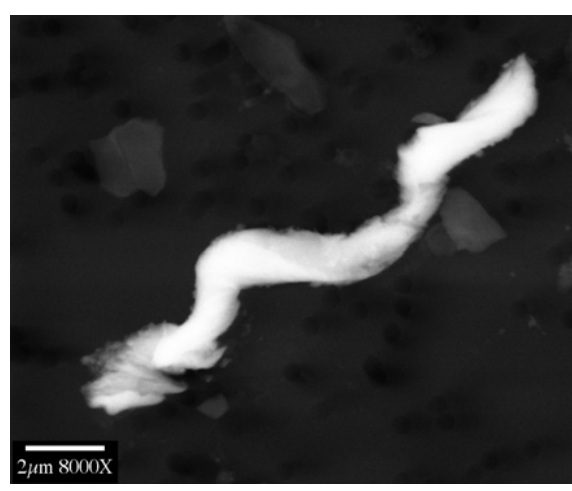

(a)

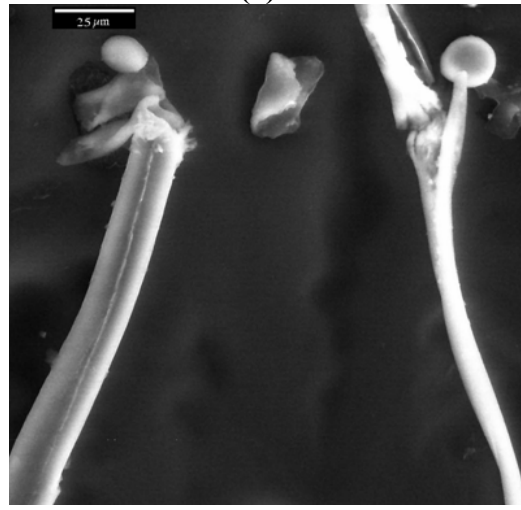

(c)

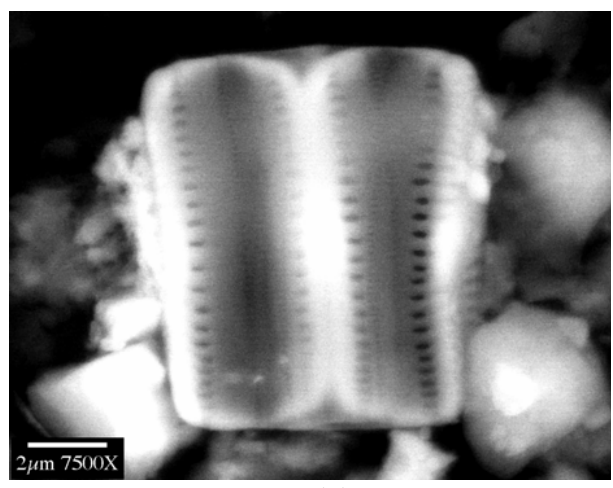

(b)

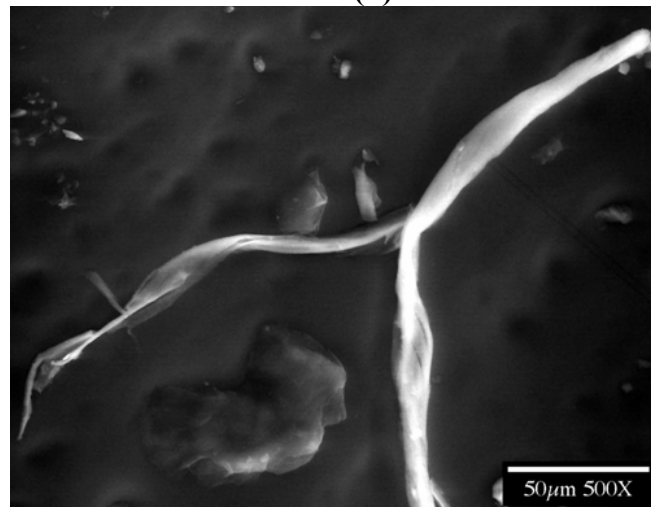

(d)

Fig. 1. ESEM images of microorganisms from different depths of Vostok ice: (a) chain of unseparated vibrions (spirilla) considered morphotypes of sulfate-reducing bacterium (cf. Desulfovibrio gigas); (1203 m); (b) intact frustules of diatom (cf. Fragilariopsis sp.) $(2827 \mathrm{~m})$; (c) filaments of cyanobacteria (cf. Plectonema radiosum) $(3592 \mathrm{~m}$ ) with disk-like cells released from filament; (d) twisted hollow sheath with false branching. Photos Courtesy: Gregory Jerman and Richard Hoover NASA/MSFC; Vostok Samples: S. Abyzov, INMI, RAS.

\section{BGD}

3, 23-70, 2006

\section{Comets,} carbonaceous meteorites, and the origin of the biosphere

\section{R. B. Hoover}

Title Page

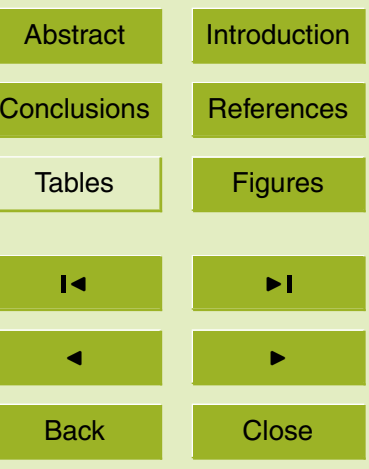

Full Screen / Esc

Print Version

Interactive Discussion 


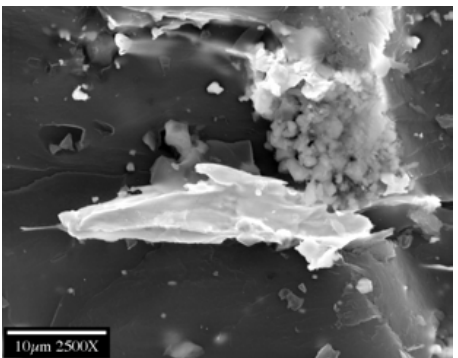

(a)

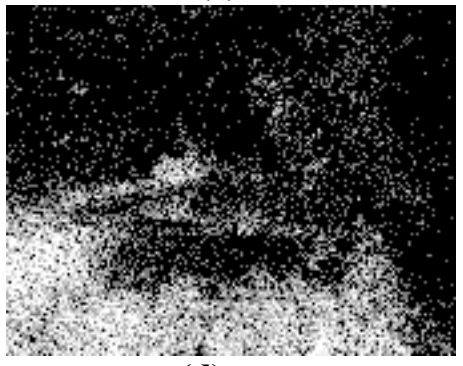

(d)

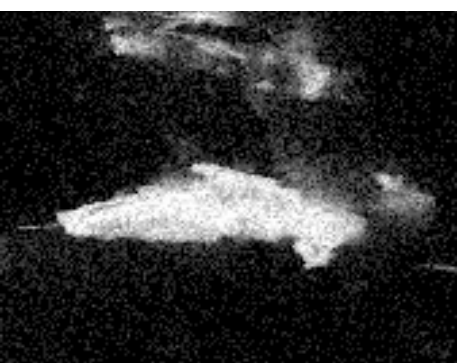

(b)

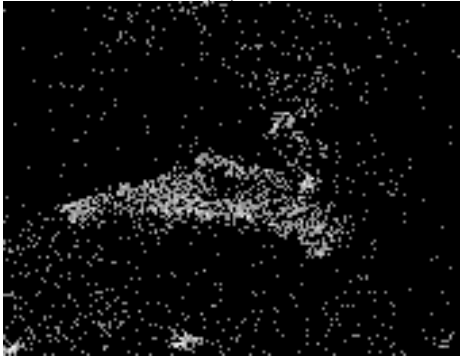

(e)

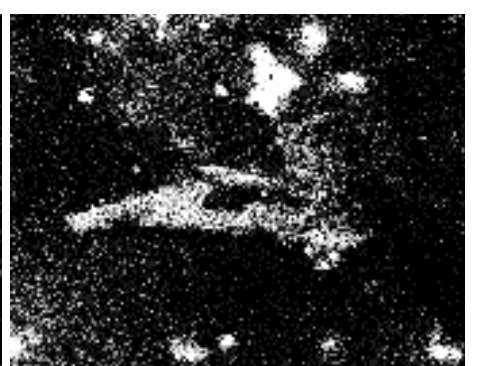

(c)

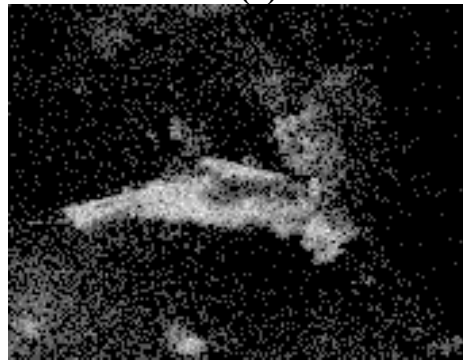

(f)
Fig. 2. (a) FESEM image of exotic microorganism from $3.3 \mathrm{~km}$ depth in Driefontein Gold Mine of Witwatersrand, South Africa for comparison with elemental 2-D x-ray maps showing distribution in the microbe of the bioaccumulated heavy metals (b) Gold; (c) Uranium; and the biogenic elements (d) Carbon; (e) Oxygen; and (f) Phosphorus. Photos Courtesy: G. Jerman and R. B. Hoover NASA/MSFC.
Comets, carbonaceous meteorites, and the origin of the biosphere

\section{R. B. Hoover}

Title Page

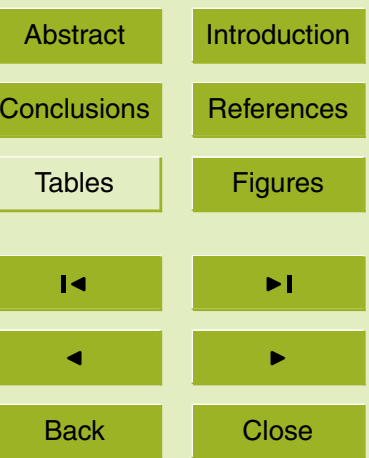

Full Screen / Esc

Print Version

Interactive Discussion 


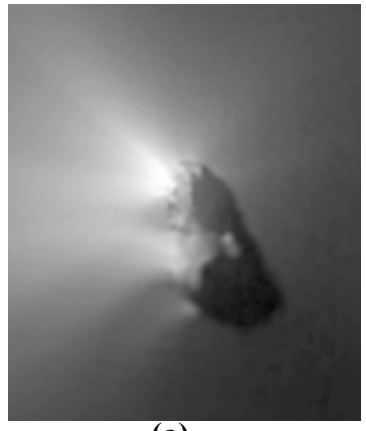

(a)

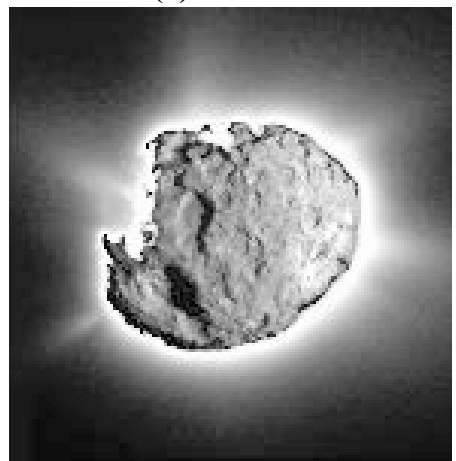

(d)

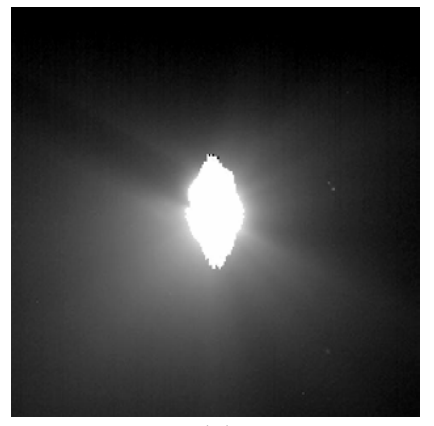

(b)

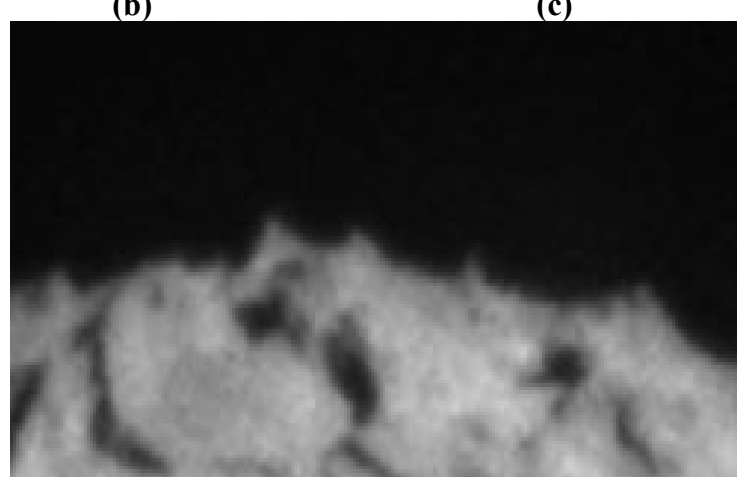

(e)
Fig. 3. (a) Giotto (Halley Multicolor Camera) image of the nucleus of Comet 1P/Halley showing bright geyser-like jets of escaping water vapor, gas, and dust. (b) Deep Impact Spacecraft images of jets from comet 9P/Tempel 1 and (c) Craters on nucleus of Tempel 1 just before the impact of the Deep Impact probe. (d) NASA Stardust Spacecraft images of jets of gas and dust escaping from comet 81P/Wild-2 and (e) pinnacles and spires up to $600 \mathrm{~m}$ height indicate that comet Wild-2 has a thick crust. Photos Courtesy: a ESA HMC and b-d NASA/JPL-Caltech.
BGD

3, 23-70, 2006

Comets, carbonaceous meteorites, and the origin of the biosphere

\section{R. B. Hoover}

Title Page

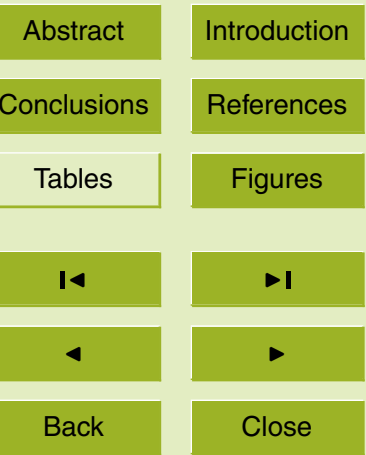

Full Screen / Esc

Print Version

Interactive Discussion 
BGD

$3,23-70,2006$

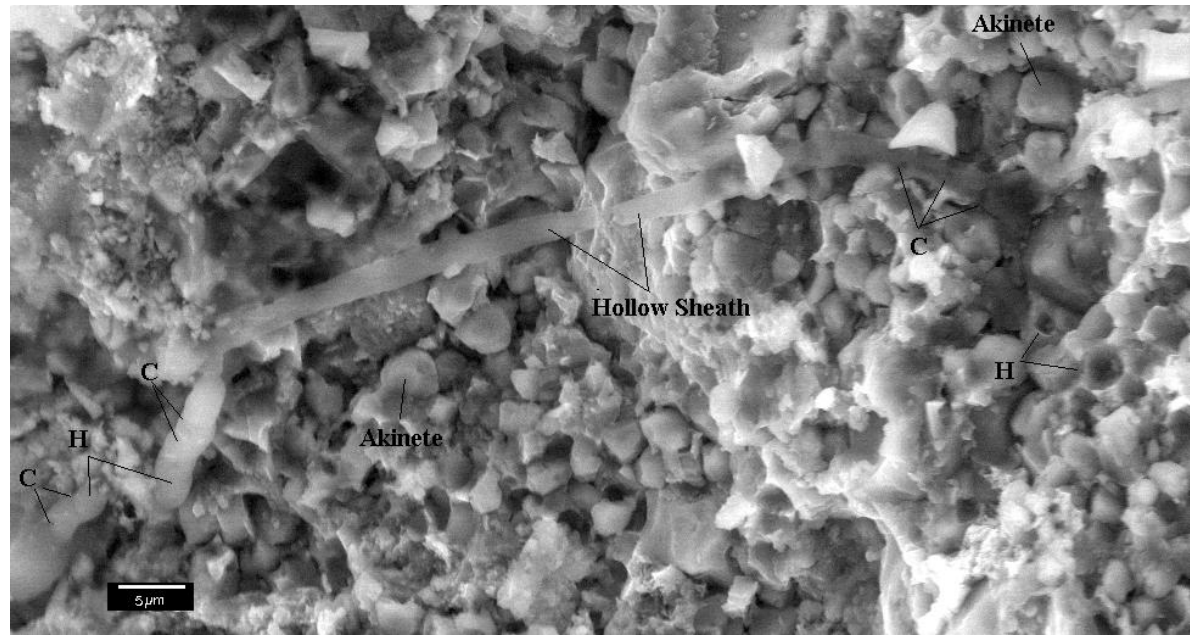

Fig. 4. Microfossil embedded in the matrix of the Murchison carbonaceous meteorite. These well-preserved mineralized remains of a filamentous prokaryote are interpreted as a Nostocacean cyanobacteria morphotype. Motile hormogonia $(\mathrm{H})$ appear to have exited the hollow sheath and cross-wall constrictions $(C)$ in the emergent hormogonia and flattened embedded sheath suggest barrel-shaped cells $(\sim 2.5-3 \mu \mathrm{m}$ diameter). Nearby spherical forms are consistent with coiling hormogonia and spores or akinetes that appear sub-spherical $(\sim 4-5 \mu \mathrm{m}$ diameter). (Scale Bar=5 $\mu \mathrm{m}$ ) Photo: NASA/MSFC.
Comets, carbonaceous meteorites, and the origin of the biosphere

R. B. Hoover

Title Page

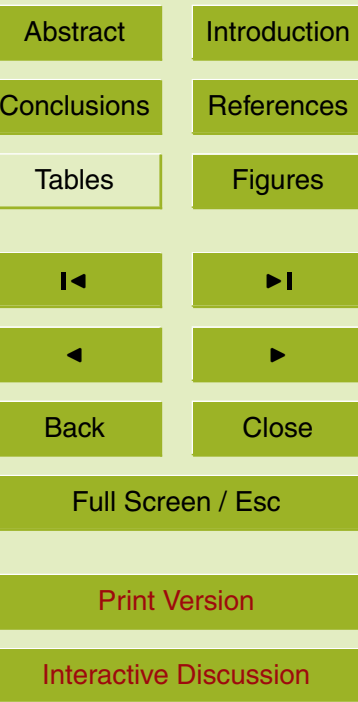



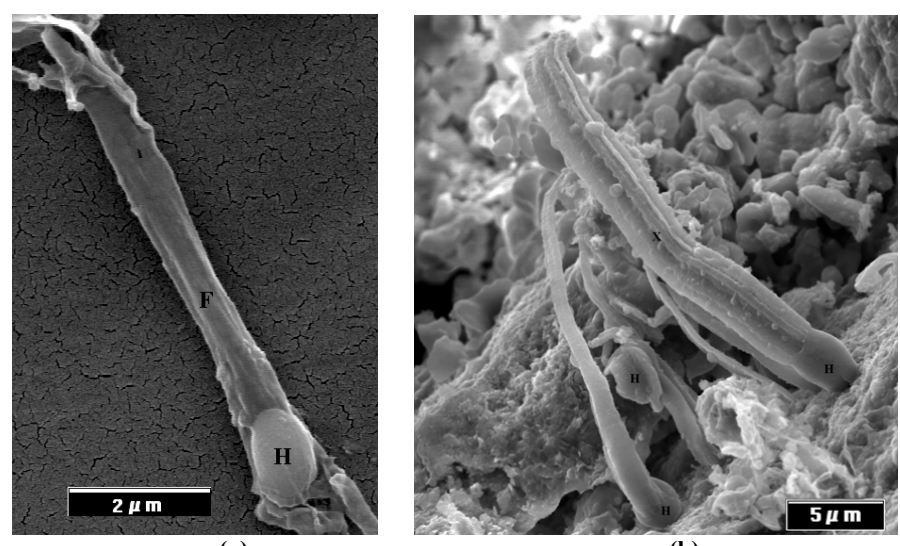

(b)

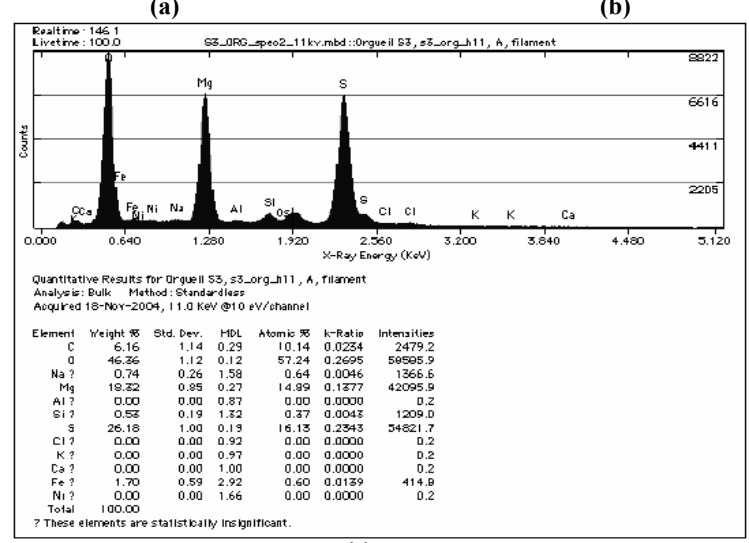

(c)

Fig. 5. FESEM images of (a) filament of modern Calothrix sp. from Little White River, Oregon with basal heterocyst and (b) mineralized remains in the Orgueil meteorite of a colony of heterocystic prokaryotes with tapering filaments and basal heterocysts $(H)$ intrepeted as indigenous microfossils of cyanobacteria Calothrix sp. (c) EDS spectrum taken at spot $\mathbf{X}$ on large mineralized Orgueil filament consistent with carbonized sheath infilled with magnesium sulfate.

\section{BGD}

3, 23-70, 2006

\section{Comets,} carbonaceous meteorites, and the origin of the biosphere
R. B. Hoover

\section{Title Page}

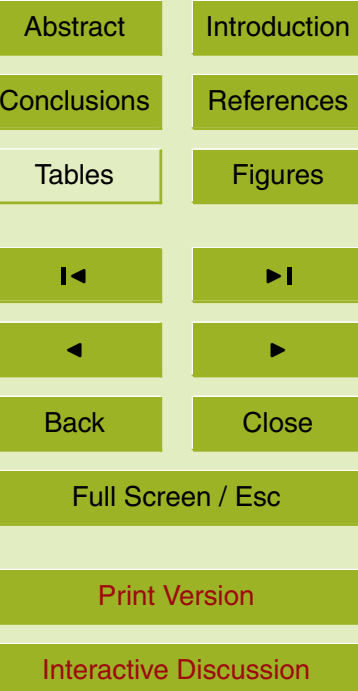

\section{EGU}




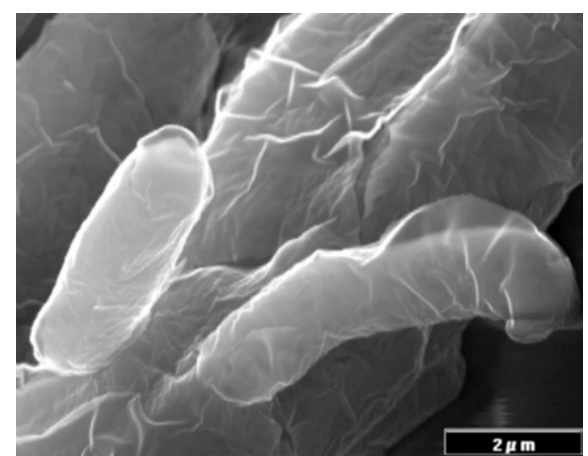

(a)

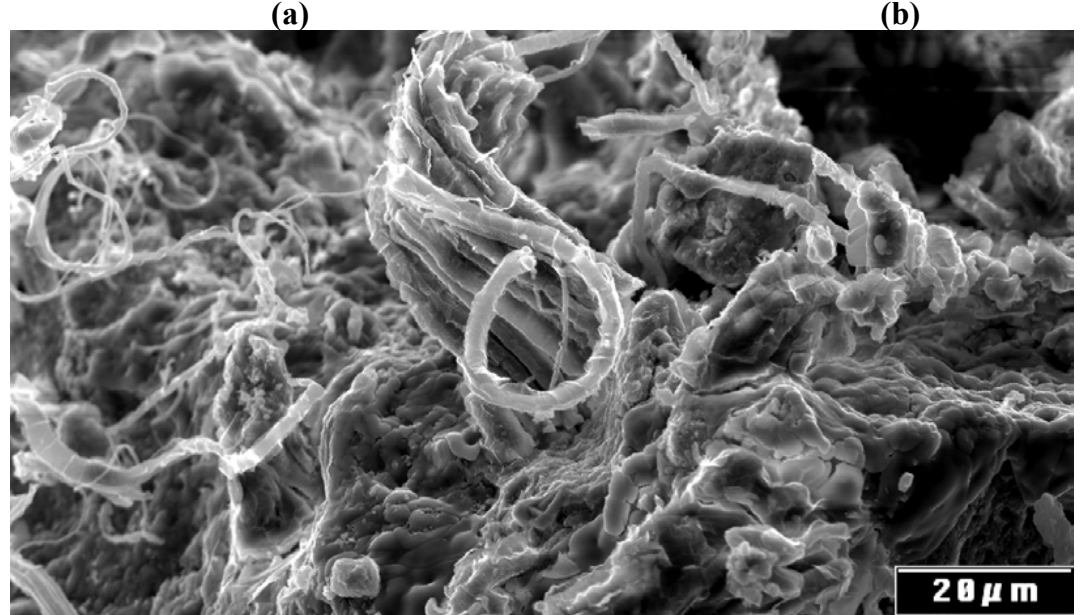

(c)

Fig. 6. Microfossils in freshly fractured Orgueil surfaces showing (a) high magnification images of the emergent trichomic cells; (b) EDS spectra of the emergent cell; and (c) mineralized remains of prokaryotic mat in the Orgueil meteorite with components similar to representatives found in a modern Microcoleus mat and fibrils of degraded sheaths.

\section{BGD}

3, 23-70, 2006

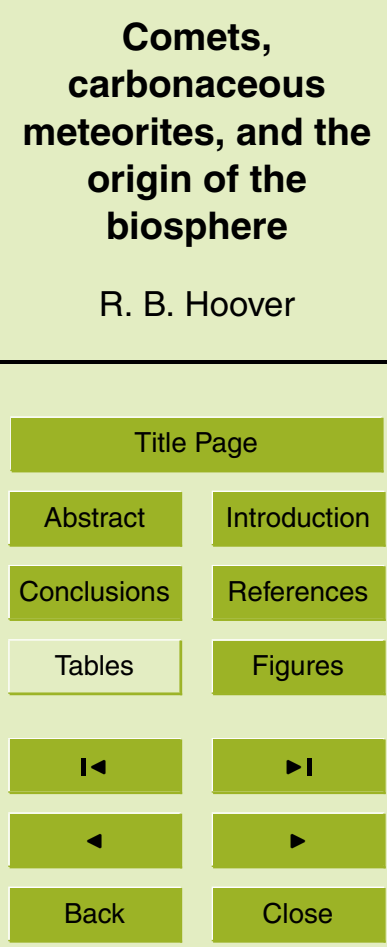

Full Screen / Esc

Print Version

Interactive Discussion 